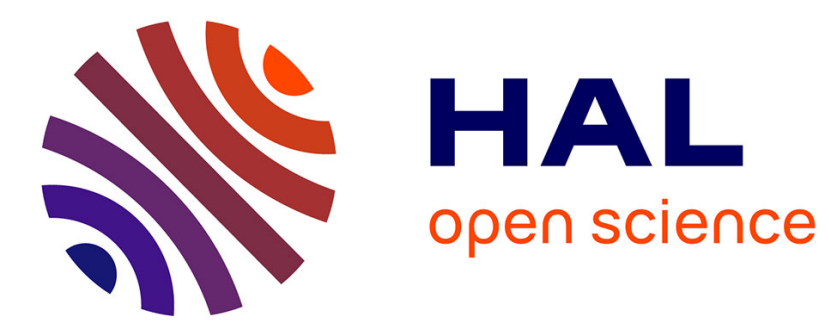

\title{
Study of post-impact behaviour of thin carbon/epoxy laminates subject to fatigue tensile loading
}

\author{
A. Rogani, Pablo Navarro, Steven Marguet, Jean-François Ferrero
}

\section{To cite this version:}

A. Rogani, Pablo Navarro, Steven Marguet, Jean-François Ferrero. Study of post-impact behaviour of thin carbon/epoxy laminates subject to fatigue tensile loading. International Journal of Fatigue, 2021, 148, pp.106134. 10.1016/j.ijfatigue.2020.106134 . hal-03176583

\section{HAL Id: hal-03176583 \\ https://hal.science/hal-03176583}

Submitted on 22 Mar 2021

HAL is a multi-disciplinary open access archive for the deposit and dissemination of scientific research documents, whether they are published or not. The documents may come from teaching and research institutions in France or abroad, or from public or private research centers.
L'archive ouverte pluridisciplinaire HAL, est destinée au dépôt et à la diffusion de documents scientifiques de niveau recherche, publiés ou non, émanant des établissements d'enseignement et de recherche français ou étrangers, des laboratoires publics ou privés. 


\title{
Study of post-impact behaviour of thin carbon/epoxy laminates subject to fatigue tensile loading
}

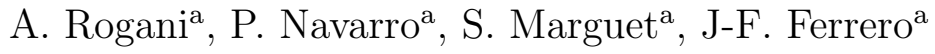 \\ ${ }^{a}$ Université de Toulouse, Institut Clément Ader, FRE CNRS 3687, \\ UPS/INSA/ISAE/Mines Albi, 3 rue Caroline Aigle, 31400 Toulouse, France
}

\begin{abstract}
This article concerns the experimental and numerical study of post-impact damage propagation in thin carbon/epoxy woven composite laminates loaded in fatigue tension. Low velocity normal drop weight impact tests are first performed. Post-impact fatigue tensile tests are then carried out. They are controlled in displacement. The monitoring is based on Digital Image Correlation and RX tomography. The influence of the impact energy and the tensile fatigue loading on the post-impact damage propagation is studied. The damage propagation is governed by matrix damage, with the emergence of tows/resin splittings and intra-tows crackings as well as delamination when the plies have different orientations. When the impact energy or the displacement level increases, the post-impact damage initiates sooner and propagate faster. In some cases, that can lead to a quasi-instantaneous failure identical to that observed for quasi-static tensile loading. The FEM based semi-continuous approach, initialy developped for the modelling of impact damage, is extended to fatigue loading for carbon/epoxy woven laminates. Fatigue damage laws, based on experimental observations are implemented. The modelling well correlates the experimental results in terms of damage
\end{abstract}


propagation scenario and speed depending on the number of cycles for laminates made up of plies with the same orientation.

Keywords: Woven composites, fatigue, digital image correlation, explicit F.E modelling, semi-continuous approach

\section{Introduction}

This article deals with the study of the post-impact behaviour of thin carbon/epoxy woven composite laminates under fatigue tensile loading. This paper is dedicated to the experimental and numerical study of samples submitted to a fatigue tensile loading after having been impacted with a low velocity in a drop tower device.

Carbon woven composite structures are widely used, especially in the field of aeronautics. However, these structures are known to be very sensitive to impact loadings. In fact, an impact can generate matrix cracking, delamination and fibre breakage. The impact can perforate the structure or the damages can be barely detectable. In any case, that induces a decrease of the mechanical properties and a loss of the strength. More, the damages can propagate if the structure is loaded after having been impacted, what can lead to the final failure.

For all these reasons, understanding and identifying the post-impact damage propagation phenomenons that occur in a carbon woven composite structures loaded with a fatigue tensile loading is important.

In general, fatigue studies on composite structures are conducted at a macroscopic scale in order to obtain the residual mechanical properties of the laminate such as the residual strength $[1,2,3,4,5]$, the residual strain 
or the residual stiffness [6]. Other authors try to characterize the fatigue behaviour of the material through the establishment of a Wöhler curve [5]. The visualization of the damage propagation is sometimes performed at a microscopic scale.

Existing studies concerns mainly compression-compression loading [7] or tension-compression loading $[8,9,10]$ rather than tension-tension loading. Indeed, the delamination that can be generated by impact can provoke local buckling when loaded in compression that could lead to an unstable propagation of the damage [11]. For instance, Melin et al. [8] concluded that, during tension-compression fatigue loading on impacted carbon/epoxy samples, the compressive part of the cycle had a more important role in failure than the tensile part. More, Beheshty et al. [7] noticed that the effects of impact damage on carbon/epoxy laminates were more severe for compressioncompression fatigue loading than for tension-compression loading.

However, few studies concern the influence of an impact on the fatigue performances of a carbon woven composite under tensile loading. Cantwell et al. [1] have shown that substituting UD carbon plies by woven plies in a laminate could improve the fatigue behavior of the composite structure and Ding et al. [2] have shown that the increase of the impact energy lead to a decrease of the residual strength of the laminate. More, the residual stiffness decreases with the impact energy [6]. It decreases in three steps : an initial fast decrease, a stable state which indicates the beginning of the transverse cracking and a final fall just before the failure.

Concerning the monitoring of the fatigue tests, various techniques are used in the literature to follow the damage during the fatigue test. For 
example, digital image correlation (DIC) $[12,13,14,15]$, acoustic emission [16] or self-heating methodology [17]. Ambu et al. [12] monitored their tension-tension fatigue tests on CFRP samples with DIC. They found that DIC was a useful to identify the roles and the influence of each failure modes on the residual properties of notched samples, the mechanisms of damage development and the strain distribution around a hole. More, De Rosa et al. [16] made a correlation between the amplitude of acoustic emission and the type of damage occurring in the laminate. Gornet et al. [17] made also a link between heating effects and damage mechanisms during fatigue loading.

Concerning the modelling of post-impact damage propagation in fatigue, the literature on the subject is barely existing. Most of the studies have been conducted on laminates with an initial defect such as notches, holes or delamination. Continuum damage modelling (CDM) is often used to model resin damaging $[18,19,20,21]$. The principle is to degrade the stiffness matrix by one or several damage variables, calculated through thermodynamical forces.

Some authors use empirical criterions, introduced by Whitney and Nuismer [22], such as the point stress criterion (PSC) and the average stress criterion (ASC). Miot [18] used the ASC method for holed and notched carbon laminates. The mean stress is calculated into a characteristic volume in order to evaluate the damage propagation. But, even if the implementation of these criterions is simple, they are very dependant on the testings parameters.

Concerning the delamination modelling, cohesive elements, introduced by Hilleborg at al. [23], are widely used for impact loading. Robinson et al. [24] used it for the modelling of delamination propagation in fatigue. 
These elements are also used in some studies to model the matrix crackings propagation. For example, Hallett et al. [25] used them for a tensile simulation on a holed sample. For this purpose, they have first noted the position of the crackings after an experimental test. Then, they meshed the sample placing the cohesive elements on potential paths of the crack propagation.

This paper focuses on the post-impact damage propagation in three thin carbon/epoxy woven composite laminates. In a first time, the objective is to investigate the propagation phenomenons specific to carbon/epoxy thin woven laminates. Low velocity impacts are first performed with a drop weight device. Then fatigue tensile tests are carried out on the impacted samples. Impact energies and levels of loading are varied. An analysis of the damage propagation scenario is based on measures from Digital Image Correlation and RX tomography. In a second time, the semi-continuous approach, already validated for post-impact quasi-static tensile loading on impacted carbon/epoxy thin woven laminates [26], is extended to fatigue loading. The innovative idea is to use the same model to calculate the damage due to an impact and its propagation. To do so, developments, based on the experimental observations are implemented. A strategy is developed in order to perform fatigue simulation on impacted samples in the explicit finite element code Radioss. Finally, the results of the simulation are compared to the experimental ones. 


\section{Experimental study}

In this section, the experimental work is described. As it is performed in several steps (manufacturing, impact tests, fatigue tests, analyse) and for the seek of clarity, the experimental path is represented on the Figure 1.

\subsection{Material and samples}

In this study, three thin carbon/epoxy woven laminates configurations are investigated. The material is the G963/913 5-harness satin prepreg provided by Hexcel. These three configurations, presented (Table 1), are commonly used in some parts of aeronautical structures, for instance helicopter blades. Configuration $\mathrm{C} 0 \mathrm{C} 0$ is made up of two carbon plies oriented at $(0 / 90)^{\circ}$, configuration $\mathrm{C} 45 \mathrm{C} 45$ is made up of two carbon plies oriented at $\pm 45^{\circ}$ and configuration $\mathrm{C} 45 \mathrm{C} 0$ is made up of one ply oriented at $(0 / 90)^{\circ}$ and one ply oriented at $\pm 45^{\circ}$.

The samples have been manufactured using a hot platen press with a curing temperature of $135^{\circ} \mathrm{C}$ and a pressure of 7 bars. The curing time was set to 90 minutes. The presence of defects has been checked with RXtomography and no voids have been observed.

The sample geometry has been set in order to perform low velocity impact test and fatigue tensile tests on the same specimen. It is presented on the Figure 2. The dimensions are $100 \mathrm{~mm} \times 300 \mathrm{~mm}$ with a thickness of 0.71

mm. The tabs are made with three plies of glass/epoxy woven oriented at $\pm 45^{\circ}$. 


\subsection{Low velocity impact tests}

The impact tests have been described in [27]. They have been conducted with the drop weight device presented on the Figure 3. The impactor has a $16 \mathrm{~mm}$ diameter steel head, with a mass of $2 \mathrm{~kg}$. Multiple impact due to the rebound is prevented. The samples are clamped on a $75 \mathrm{mmx} 125 \mathrm{~mm}$ rectangular frame. Impact velocities and corresponding impact energies are varied. Five impact energies have been tested (Table 2). They have been chosen to have several levels of damage for each configuration in order to study how the propagation initiates.

These impact tests have been carried out in the same experimental campaign than presented in [27]. The damage shapes and sizes are very repeatable. The fracture surfaces of the impacted samples are presented on the Figures 4,5 and 6. The damage has only been characterized visually : as there are only two plies, the most important damages can be measured with this method. The values in yellow corresponds to the size of the damaged area in the upper ply and the values in white are the sizes of the fibres breakages in each ply.

For the $\mathrm{C} 0 \mathrm{C} 0$ and $\mathrm{C} 45 \mathrm{C} 45$ configurations, cross-shaped fibres breakages oriented in the bundles directions are observed in the upper and lower plies. For the $\mathrm{C} 45 \mathrm{C} 0$ configuration, the fibres failure are oriented at $(0 / 90)^{\circ}$ in

the lower ply and are oriented with an angle that varies between $\pm 45^{\circ}$ and $(0 / 90)^{\circ}$ in the upper ply. Indeed, the damage propagation in the upper ply is influenced by the directions of the lower ply, as it has been shown in [27] that the damage initiates in this lower ply. The size of the damages increase with the energy of impact until an energy of $4 \mathrm{~J}$ for which the impactor totally 
perforates the sample.

\subsection{Fatigue tensile tests on impacted samples}

\subsubsection{Characteristics of the fatigue tensile tests}

The fatigue tensile tests on impacted samples are conducted with an INSTRON machine with a load cell of $250 \mathrm{kN}$ (Figure 7). They are controlled in displacement. The imposed cycle is presented on the Figure 8. It is typical of the loading of an helicopter blade. A quasi-static rise is imposed until $\Delta \mathrm{L}_{\text {sta }}$ and a cycle of half-amplitude $\Delta \mathrm{L}_{\mathrm{dyn}}$ is imposed with a frequency of $15 \mathrm{~Hz}$.

The load ratio is defined as $\mathrm{R}=\Delta \mathrm{L}_{\text {dyn }} / \Delta \mathrm{L}_{\text {sta }}=0.9$. The level of the fatigue load is set as a function of the break displacement in quasi-static tension $\Delta \mathrm{L}_{\text {rupt QS }}$ measured in [27]: $\Delta \mathrm{L}_{\text {sta }}=25 \% \Delta \mathrm{L}_{\text {rupt QS }}$ for C45C45 and $\Delta \mathrm{L}_{\text {sta }}$ $=40 \% \Delta \mathrm{L}_{\text {rupt QS }}$ for $\mathrm{C} 0 \mathrm{C} 0$ and $\mathrm{C} 45 \mathrm{C} 0$.

The reaction load is measured during the test. The strain fields of the samples are measured by the use of Digital Image Correlation (DIC). To do so, the tests are recorded with two cameras, filming the front and the back face of the sample (Figure 7).

The influence of the impact energy and fatigue cycle level on the postimpact damage propagation is studied. The values are gathered in the Table 3 .

Three tests have been conducted for each configuration in order to check the repeatability. 


\subsubsection{Monitoring of the damage propagation}

During the fatigue tests, the damage propagation is monitored with DIC in order to study the progression depending on the number of cycles.

To do so, the correlation quality factor Sigma calculated by the DIC is used. The more its value decreases, the more the correlation quality is high. When damage appears in the sample, the value of the quality factor increases $[13,14,15]$. For instance, Figure 9 shows the damage of a an impacted sample of configuration $\mathrm{C} 45 \mathrm{C} 45$ during a fatigue tensile loading. In order to control that measure, the sample has been subject to RX tomography. The presence of tows/resin splittings and intra-tows crackings is observed. The parallel with the value of Sigma indicates that if the quality factor reaches its maximal value (in red on the figure) that corresponds to tows/resin splittings and if the software is unable to calculate its value (in grey on the figure), that corresponds to intra-tows crackings.

\subsubsection{Configuration $C 45 C 45$}

For the configuration $\mathrm{C} 45 \mathrm{C} 45$, the post-impact damage propagates at $\pm 45^{\circ}$ until it reaches the edges of the sample (Figure 10). Figure 11 shows the value of the load measured during the test versus the number of cycles. In can be divided in four steps (Figure 12) :

1. A very high initial decrease explained in the literature by an important decrease of stiffness and a fast development of residual strains at the beginning of the test before stabilization [28]

2. A slower decrease due to the damage progression

3. A high diminution when the damage propagation reaches the edges of 
the sample

4. A stabilization for which the damage no longer progress

The propagation initiates with tows/resin splittings from each tip of the initial fibres breakages. They progress transversely to the initial breakages in order to join into a unique point. Then, they propagate at $\pm 45^{\circ}$ from the point of intersection and intra-tows crackings initiate. These two types of matrix damaging propagate at $\pm 45^{\circ}$ but the intra-tows crackings propagation is much slower. Finally, the splittings reach the edges of the samples, following by the crackings some number of cycles later. No fibres breakages are visible by RX tomography after the fatigue loading (Figure 9). In fact, the damage propagation is governed by the resin. That explains why, for all the tested samples, when the damage propagation reaches the edges of the sample, the load is not equal to zero but is about $2.2 \mathrm{kN}$ (Figure 11).

More, the increase of the impact energy or the displacement level leads to a decrease of the number of cycles necessary to initiate the damage propagation and a faster propagation of the damage (Figure 11 and Table 4).

However, these values converge with the increase of the impact energy. In fact, from an energy of $4 \mathrm{~J}$, the impactor perforates the laminates and the size of the impact damage is roughly the same (Figure 5).

Finally, for the lower impact energy $\left(\Delta \mathrm{L}_{2} ; 2.25 \mathrm{~J}\right)$ and displacement level $\left(-20 \% \Delta \mathrm{L}_{2} ; 4 \mathrm{~J}\right)$, the post-impact damage barely propagates (Figure 13$)$. The tests was stopped after $10^{6}$ cycles. The load practically does not decrease during the fatigue test which is representative of few damage in the sample (Figure 11). The post-impact damage propagation also initiates with tows/resin splittings from each tip of the initial fibres breakages. However, 
they propagate both transversely and in the direction of the initial breakages. Their progression is very slow and the intra-tows crackings initiate very late in comparison to the previous scenario (about $10^{6}$ cycles). The propagation is not localized and several preferential areas of damage propagation are noticeable in this case (Figure 14). Hence, the samples does not crack on a $\pm 45^{\circ}$ band.

\subsubsection{Configuration COCO}

For the configuration $\mathrm{C} 0 \mathrm{C} 0$, the post-impact damage propagates vertically (Figure 15).

The DIC indicates the presence of vertical areas strongly loaded in shear (Figure 16). The damage propagates into this areas, where the principal strain directions are oriented at $\pm 45^{\circ}$. As for the configuration $\mathrm{C} 45 \mathrm{C} 45$, the damage propagation is governed by the damage of the resin. In fact, the RX tomography, performed after the tests, shows the emergence of tows/resin splittings and intra-tows crackings (Figure 17).

Figure 18 shows the evolution of each type of damage versus the number of cycles. Damage 1 represents tows/resin splittings and Damage 2 represents intra-tows crackings.

The progression in fatigue tension of tows/resin splittings and intra-tows crackings in the sample of configuration $\mathrm{C0C0}$ is identical. The shape of their length curves is similar. Nevertheless, the splittings initiate sooner and faster than the intra-tow crackings.

More, the increase of the initial impact energy or the displacement level leads to a faster propagation of the post-impact damage and greatest final 
sizes of tows/resin splittings and intra-tows crackings. However, a gap is noticeable between $(2.25 \mathrm{~J} ; 3 \mathrm{~J})$ and $(4 \mathrm{~J} ; 6.25 \mathrm{~J} ; 9 \mathrm{~J})$. From an energy of 4 $J$, the impactor perforates the laminate. So, for the three higher energies, the initial impact damage size is roughly the same and the post-impact fatigue behaviour of the sample converges.

For the higher loading $+25 \% \Delta \mathrm{L}_{3}$, the fracture surface (Figure 19) is identical to that observed for impacted samples subject to quasi-static tensile loading and described in [27]. Fibres breakages propagate in the direction perpendicular to the loading and the sample breaks almost instantly after the beginning of the fatigue loading $\left(\mathrm{N}_{\text {failure }}=50\right)$.

\subsubsection{Configuration $C 45 C 0$}

For the configuration $\mathrm{C} 45 \mathrm{C} 0$, the post-impact damage propagates vertically in the lower ply oriented at $(0 / 90)^{\circ}$ and propagates at $\pm 45^{\circ}$ in the upper ply oriented at $\pm 45^{\circ}$ (Figure 20). Contrary to $\mathrm{C} 45 \mathrm{C} 45$ and $\mathrm{C} 0 \mathrm{C} 0$, the observation of the damage indicates the development of delamination.

The damage propagation scenario is described in detail on the Figure 21. Several samples have been subject to fatigue tensile loading. The tests have been stopped at $10^{5}, 5.10^{5}$ and $2.10^{6}$ in order to analyze the damage propagation in the sample by RX tomography. The damage propagation begins in the lower ply oriented at $(0 / 90)^{\circ}$ : tows/resin splittings initiate and propagate vertically as observed for the configuration $\mathrm{C} 0 \mathrm{C} 0$. That induces the initiation of delamination between the two carbon plies. Then, intra-tows crackings initiate and propagate vertically. However, unlike the configuration $\mathrm{C} 0 \mathrm{C} 0$, the splittings progress vertically and also horizontally, as for the 
delamination. At the same time, in the ply oriented at $\pm 45^{\circ}$, intratows cracks propagates at $\pm 45^{\circ}$. Finally, all these damages propagate simultaneously during the fatigue loading. The resin damage in each ply is delimited by the delaminated area.

This damage propagation scenario indicates that each ply of the configuration $\mathrm{C} 45 \mathrm{C} 0$ behaves individually. It seems to be due to the delamination between the two plies which dissociates the specific behaviour of each orientation.

The influence of the impact energy on the damage propagation is observed on RX tomography performed after $2.10^{6}$ cycles (Figure 22). The increase of the impact energy leads to a larger delaminated area and a more important matrix damage in the lower ply. Indeed, the curves of damage length depending on the number of cycles show a faster propagation of the tows/resin splittings and intra-tows crackings in the lower ply with the increase of the impact energy or the level of cycle level (Figure 23).

As for the configuration $\mathrm{C} 45 \mathrm{C} 45$ and $\mathrm{C} 0 \mathrm{C} 0$, the speed of damage propagation converges from an impact energy of $4 \mathrm{~J}$ for which the impactor perforates the laminates.

For the higher loading level $+5 \% \Delta \mathrm{L}_{4}$, the sample breaks instantly after the beginning of the fatigue loading (Figure 24). Fibre breakages propagate between $0^{\circ}$ and $\pm 45^{\circ}$ as for an impacted samples loaded with a quasi-static tensile loading, as shown in [27]. 


\section{Numerical study}

\subsection{Semi-continuous approach}

In this part, the semi-continuous modelling strategy is extended to fatigue tensile simulation on carbon/epoxy woven laminates. It has been developed initially for impact loadings $[29,30,31,32]$ and extended to post-impact quasi-static tensile loadings on woven laminates [26].

The modelling strategy is to decouple the resin and tows behaviour in order to represent simultaneously the damaged resin and the undamaged fibers tows (Figure 25). For this purpose, a specific finite element is developed. It relies on a truss structure of rod elements, modelling the woven fabric bundles and following the woven pattern geometry, and a shell element, representing the epoxy matrix. A specific interface element that have been developped in a previous work [30], with an elastic damaging behaviour based on a bilinear cohesive law, connects the plies and represent the delamination.

The rod elements have an elastic and brittle behaviour. Their breakage are calculated through tensile and compressive strain criterions. The resin has an elastic and isotropic behaviour with an anisotropic damage in each direction of the woven through two damage variables, that are function of thermodynamical forces. It has also a pseudo-plastic behaviour in plane shear with a shear damaging law. It is calculated through two damage variables which represent respectively tows/resin splittings and cracks into bundles [26].

This original element formulation, so as the fatigue law presented in the next section, have been implemented in the explicit solver RADIOSS with the use of user FORTRAN subroutines in a 8-nodes "user element". 


\subsection{Propagation laws in fatigue}

\subsubsection{Resin damaging}

The fatigue tensile tests, performed in 2.3, have shown that the postimpact damage propagation was governed by shear damaging with the development of tows/resin splittings and intra-tows crackings propagation in the laminates. These two types of resin damaging types follow the same direction and have a similar behaviour. However, the splittings initiate first and propagate faster than the crackings.

As for the quasi-static modelling, the propagation in fatigue of resin dam-

aging is based on thermodynamical forces. Two fatigue laws $Y_{x y}-N_{\text {resin } a}$ and $Y_{x y}-N_{\text {resin } b}$ are implemented for the shell element. $N_{\text {resin a }}$ and $N_{\text {resinb }}$ are the number of cycles necessary to initiate respectively the tows/resin splittings and the intra-tows crackings. They are expressed as Basquin curves

$$
N_{\text {resin } a}=\left(\frac{Y_{a}}{Y_{x y}-Y_{a}^{0}}\right)^{\frac{1}{\alpha}} \text { and } \quad N_{\text {resinb }}=\left(\frac{Y_{b}}{Y_{x y}-Y_{b}^{0}}\right)^{\frac{1}{\beta}}
$$

where $Y_{a}, \alpha, Y_{b}$ and $\beta$ are parameters of the fatigue laws. Threshold values $Y_{a}^{0}$ and $Y_{b}^{0}$ have also been added for each damage type [18, 19]. These parameters are identified tests on the configurations $\mathrm{C} 45 \mathrm{C} 45$ and $\mathrm{C} 0 \mathrm{C} 0$.

\subsubsection{Damage accumulation}

The damage accumulation in the shell element during the fatigue tensile simulation is taken into account by a simple Miner's rule. A variable $D_{m}$ is introduced such as :

$$
D_{m}=\sum_{i} \frac{n_{i}}{N_{i}}
$$


where $n_{i}$ is the number of cycles realized at an energy release rate $Y_{i}$ for which the number of cycles at failure is $N_{i}$. Thus, if $D_{m}=1$, the the shell element is deleted.

\subsection{Strategy of post-impact fatigue tensile simulation}

In this section, the samples are modeled in the explicit solver RADIOSS with 8-nodes "user elements". The mesh size used for the modeling is equal to the physical pattern of the carbon woven which is $1,4 \mathrm{~mm}$. The number of elements is 20500 which corresponds to 30900 nodes.

\subsubsection{Principle}

The principle of the simulation strategy is to find in the model the shell element which requires the lowest number of cycles to reach the breakage. That amounts to find the number of cycles $N_{\text {elem }}$ which verifies :

$$
N_{\text {elem }}=\min _{j \in m e s h}\left(1-D_{m}(j)\right) *\left(\frac{Y_{i}}{Y_{j}-Y_{i}^{0}}\right)^{\frac{1}{k}}
$$

with $i=a$ or $b$ and $k=\alpha$ or $\beta$.

\subsubsection{Strategy}

The strategy is implemented through a user law in the explicit finite

element code Radioss. The user law is made up of a quasi-static and a fatigue module. The steps of the simulation are :

1. First a quasi-static rise is numerically performed until the maximum displacement of the experimental fatigue cycle : $\Delta L=\Delta L_{s t a}+\Delta L_{d y n}$. A first calculation of strains and thermodynamical forces is done for each element of the model. 
2. Then, the calculation goes into the fatigue module :

(a) The breakage number of cycles is calculated for each shell element of the model in order to find the first element to fail (Equ. 3).

(b) If the damage corresponds to :

- tows/resin splitting : the shell element does not have to be entirely deleted because the intra-tows crackings did not appear yet. The shear damage variable of this element is set to 0.5 .

- intra-tows crackings : the shell element is entirely deleted ( the shear damage variable of this element is set to 1 ).

(c) Once the shell element is damaged, the number of cycles and all the variables $D_{m}$ (in order to simulate the damage accumulation) are uploaded.

3. Before moving to the next iteration, the calculation goes again into the quasi-static module in order to get the new strains and thermodynamical forces of each element of the model.

\subsection{Fatigue tensile simulations on impacted carbon woven samples}

\subsubsection{Identification of the resin damaging laws}

In this paragraph, the propagation laws presented in 3.2.1 are identified and validated through simulations on impacted samples of configuration C45C45 and C0C0. The impact energies and displacement levels used for these simulations are the same as in the experimental part (Table 3). 
The propagation laws in fatigue $Y_{x y}-N_{c y c l e s}$, identified for tows/resin splittings and intra-tows crackings, are presented on the Figure 26.

\subsubsection{Validation of the resin damaging laws}

Configuration C45C45.

For the configuration $\mathrm{C} 45 \mathrm{C} 45$, the post-impact damage scenario given by the calculation is presented on the Figure 27. The damage propagates at $\pm 45^{\circ}$ in the same way as the experimental scenario described in the paragraph 2.3.3.

Furthermore, the number of cycles required to reach the edges of samples obtained with the modelling are very close to the values experimentally obtained (Tables 5-6).

Figure 28 shows the energy release rates calculated at the boundary of the post-impact damage at the end of the quasi-static rise. The values are more important with the increase of the post-impact damage size or the displacement level. That explains why the damage propagates faster with the increase of the initial damage size or the displacement level (Tables 5-6).

More, as for the experimental testings, the post-impact damage barely propagates for the couples $\left(\Delta \mathrm{L}_{2} ; 2.25 \mathrm{~J}\right)$ and $\left(-20 \% \Delta \mathrm{L}_{2} ; 4 \mathrm{~J}\right)$ (Figure 29$)$. The splittings progress very slowly and intra-tows crackings initiate very late ( $10^{6}$ cycles). The simulation has been stopped at $2 \cdot 10^{6}$ cycles.

This slow evolution can also be explained with the observation of the energy release rates calculated in the sample. For instance, for a low dis-

placement level $\left(-20 \% \Delta \mathrm{L}_{2}\right)$, once the tows/resin start to propagate, these values are lower than the values obtained for a higher displacement level (Fig- 
ure 30). They are below the threshold value $Y_{0}^{b}$ required to initiate intra-tows crackings. As a consequence, they do not emerge immediately and need a high number of cycles to appear.

\section{Configuration COCO.}

For the configuration $\mathrm{C} 0 \mathrm{C} 0$, the post-impact damage propagation scenario obtained with the modelling is in accordance with the experimental results presented in the paragraph 2.3.4. Tows/resin splittings and then intra-tows crackings propagate vertically (Figure 31).

Furthermore, the post-impact damage propagation velocity well correlates the velocity experimentally obtained. The evolution curves depending on the number of cycles are presented on the Figure 32 for the tows/resin splittings and then intra-tows crackings.

They propagate very quickly in the 100000 - 200000 first cycles before stabilizing progressively. In fact, shear strains in the resin at the tip of the damage propagation decrease as the simulation progresses (Figure 33). That leads to a decrease of the energy release rates in the resin. So, the number of cycles required to initiate splittings and crackings increases. Finally, for $10^{7}$ cycles, energy release rates calculated at the tip of the splittings are lower to the damages threshold values $Y_{0}^{a}$ and $Y_{0}^{b}$.

With an increase of the initial damage size or the imposed displacement, the shear strains calculated at the tip of the post-impact damage at the end of the quasi-static rise increase. The energy release rates are higher and the resin damaging initiates faster (Figure 34).

However, for the highest displacement level $+30 \% \Delta \mathrm{L}_{3}$, fibres breakages 
propagate horizontally during the quasi-static rise before the start of the fatigue calculation (Figure 35). The fibres reach the tensile strain limit, so that the sample breaks as in quasi-static [26].

\subsubsection{Configuration $C 45 C 0$}

The semi-continuous modelling is validated for fatigue tensile simulations on carbon/epoxy woven laminates made up of two identical plies. However, a limitation is reached when the two plies have a different orientation. For instance, the Figure 36 shows the result of a simulation performed on a sample of configuration $\mathrm{C} 45 \mathrm{C} 0$ initially impacted with an energy of $6.25 \mathrm{~J}$ and subjected to a displacement level $\Delta \mathrm{L}_{4}$. The matrix damage in the two plies is not enough developed in comparison to what observed experimentally. This difference is due to the fact that delamination has not been implemented yet in the modelling.

Indeed, in order to verify that delamination has to be accounted for, the strategy of post-impact fatigue tensile simulation presented in 3.3.2 has been modified. As for the shell elements, a simple Basquin-type fatigue propagation law is introduced for each interface element of the model. For this purpose, the number of cycles to failure is calculated through :

$$
N_{\text {failure interface }}=\left(1-D_{\text {minterface }}\right)\left(\frac{\sigma_{6}}{\sigma_{I I}}\right)^{\frac{1}{\lambda}}
$$

where $\sigma_{I I}$ is the mode II stress calculated in the cohesive interface, $\sigma_{6}$ is the failure stress at $10^{6}$ cycles and $\lambda$ is a parameter of the fatigue law. During the fatigue module of the strategy, the number of cycles to failure of the interface is also taken into account in order to find the element which requires the 
lowest number of cycles to reach the failure.

The results are presented here in order to see if the delamination propagation in fatigue has a big influence on the phenomenon. Thus, the values for the parameters of the delamination fatigue law have not been identified very precisely. With this modified strategy, the simulation performed on the sample of configuration $\mathrm{C} 45 \mathrm{C} 0$ gives now better results. Horizontal and vertical delaminated areas are observed during the simulation (Figure 37). The two carbon plies are locally debonded, so that strains and energy release rates in the $\mathrm{C} 0$ carbon plyare higher. That leads to bigger vertical damages in this ply. However, the matrix damage propagates only vertically in the $\mathrm{C} 0$ ply and is not as much developed in the C45 ply as experimentally.

\section{Conclusion}

The post-impact damage propagation in thin carbon/epoxy woven composite laminates under tensile fatigue loading has been investigated in this article. The first main contribution of this work is to provide a study of the influence of the initial damage size, through the variation of the impact energy, and the level of loading has been performed. A precise analysis of the damage propagation scenario has also been provided. The observation of the propagation has been performed with RX tomography and DIC. From this experimental study, significant results can be highlighted.

The damage propagation in fatigue in the configuration $\mathrm{C} 45 \mathrm{C} 45$ and $\mathrm{C} 0 \mathrm{C} 0$ is governed by the resin damaging. Two types of damaging have been identified : tows/resin splittings and intra-tows crackings. The splittings appear always before the crackings and these two damages evolve out of time. 
For C45C45, the damage initiates from each tip of the initial damage in order to form a rhombus and then propagates at $\pm 45^{\circ}$ until the edge of the sample. But, if the initial damage size or the loading level is too small, the damage barely propagates. For $\mathrm{C} 0 \mathrm{C} 0$, the resin damaging propagates vertically in the areas strongly loaded in shear. It quickly evolves in the 200000 first cycles of fatigue before stabilizing due to the decrease of the resin strains at the tip of the propagation as the testing continues. However, if the imposed displacement is too high, the behaviour is identical to the one observed in quasi-static. Fibers breakages propagate horizontally very quickly at the beginning of the test. For the configuration $\mathrm{C} 45 \mathrm{C} 0$, the post-impact damage propagation is a combination of the evolutions described above. First, resin damaging propagates vertically and horizontally in the carbon ply oriented at $(0 / 90)^{\circ}$. Then, resin damaging propagates at $\pm 45^{\circ}$ in the ply oriented at $\pm 45^{\circ}$. In fact, delamination dissociates the two plies : each ply behaves individually and is guided by the delamination.

The second main contribution is to provide a description of a modelling strategy that is able to represent the damage induced by an impact and also the propagation of this damage in fatigue loading with the same model. It is innovative because the literature dealing with the modeling of the postimpact damage propagation in carbon/epoxy woven laminates subject to tensile loading is barely existing. In fact, most of the studies are conducted on laminates with notches, holes or pre-existing delamination.

This original modeling strategy is developed at the mesoscopic scale. Indeed, the semi-continuous modelling has been extended to fatigue tensile simulations. The resin damage is implemented for the shell elements through 
two fatigue laws $Y_{x y}-N_{\text {resin } a}$ and $Y_{x y}-N_{\text {resin } b}$ based on thermodynamical forces. The damage accumulation is taken into account by a simple Miner's rule. Finally, the strategy is to find in the sample the shell element which requires the lowest number of cycles to reach the breakage and to delete it.

The laws have been identified through several simulations on impacted samples of configuration $\mathrm{C} 0 \mathrm{C} 0$ and $\mathrm{C} 45 \mathrm{C} 45$. The modelling is validated in terms of damage propagation scenario, number of cycles at initiation and speed for woven carbon/epoxy laminates made up of plies with the same orientation. However, for the $\mathrm{C} 45 \mathrm{C} 0$ configuration, it appears that delamination is a key phenomenon. Thus a fatigue law has to be properly implemented in order to represent the mechanisms leading to the post-impact fatigue behaviour of this configuration.

\section{Acknowledgment}

This work was granted access to the HPC resources of CALMIP supercomputing center under the allocation 2019-P09105. 


\section{References}

[1] W. Cantwell, P. Curtis, J. Morton, Post-impact fatigue performance of carbon fibre laminates with non-woven and mixed-woven layers, Composites 14 (3) (1983) $301-305$.

[2] Y. Ding, Y. Yan, R. McIlhagger, Effect of impact and fatigue loads on the strength of plain weave carbon-epoxy composites, Journal of Materials Processing Technology 55 (2) (1995) 58 - 62.

[3] K.-W. Kang, J.-K. Kim, Fatigue life prediction of impacted carbon/epoxy laminates under constant amplitude loading, Composites Part A: Applied Science and Manufacturing 35 (5) (2004) 529 - 535.

[4] K. Vallons, A. Behaeghe, S. Lomov, I. Verpoest, Impact and post-impact properties of a carbon fibre non-crimp fabric and a twill weave composite, Composites Part A: Applied Science and Manufacturing 41 (8) (2010) 1019 - 1026.

[5] A. Komus, Fatigue behaviour of a barely visible impact damaged carbon fibre reinforced epoxy laminate, Ph.D. thesis, University of Manitoba (2010).

[6] D. Sudevan, R. Prakash, M. Kamaraj, Post-impact fatigue response of cfrp laminates under constant amplitude and programmed falstaff spectrum loading, Procedia Engineering 101 (2015) 395 - 403.

[7] M. Beheshty, B. Harris, T. Adam, An empirical fatigue-life model for high-performance fibre composites with and without impact damage, 
Composites Part A: Applied Science and Manufacturing 30 (8) (1999) $971-987$.

[8] L. Melin, J. Schön, T. Nyman, Fatigue testing and buckling characteristics of impacted composite specimens, International Journal of Fatigue 24 (2) (2002) $263-272$.

[9] I. Kimpara, S. Hiroshi, Post-Impact Fatigue Behavior of Woven and Knitted Fabric CFRP Laminates for Marine Use, Springer Netherlands, 2010, Ch. 6, pp. 113-132.

[10] C. Garnier, M.-L. Pastor, B. Lorrain, O. Pantalé, Fatigue behavior of impacted composite structures, Composite Structures 100 (2013) 443 450.

[11] G. Davies, P. Irving, 9 -, in: Polymer Composites in the Aerospace Industry, Woodhead Publishing, 2015, Ch. 9, pp. 231 - 259.

[12] R. Ambu, F. Aymerich, F. Bertolino, Investigation of the effect of damage on the strength of notched composite laminates by digital image correlation, The Journal of Strain Analysis for Engineering Design 40 (5) (2005) 451-461.

[13] W. Leser, J. Newman, W. Johnston, Fatigue crack closure analysis using digital image correlation, Tech. rep., NASA (2010).

[14] M. Iadicola, T. Foecke, 2d dic crack tip tracing under mode i loading, in: Annual International DIC Society Conference, 2017. 
[15] K. Conway, Multiscale behavior of fused deposition additively manufactured thermoplastic cellular materials, Ph.D. thesis, Clemson University (2018).

[16] I. De Rosa, H. Dhakal, C. Santulli, F. Sarasini, Z. Zhang, Post-impact static and cyclic flexural characterisation of hemp fibre reinforced laminates, Composites Part B: Engineering 43 (3) (2012) 1382 - 1396.

[17] L. Gornet, D. Sudevan, P. Rozycki, A study of various indicators to determine the fatigue limit for woven carbon/epoxy composites under self heating methodology, Procedia Engineering 213 (2018) 161 - 172.

[18] S. Miot, Rupture de structures composites stratifiées sous chargements statique et de fatigue, Ph.D. thesis, Université d'Aix-Marseille (2009).

[19] C. Hochard, Y. Thollon, A generalized damage model for woven ply laminates under static and fatigue loading conditions, International Journal of Fatigue 32 (1) (2010) 158 - 165.

[20] J. Maire, J. Chaboche, A new formulation of continuum damage mechanics (cdm) for composite materials, Aerospace Science and Technology 1 (1996) 247-257.

[21] L. Marcin, Modélisation du comportement, de l'endommagement et de la rupture de matériaux composites à renforts tissés pour le dimensionnement robuste de structures, Ph.D. thesis, Université Bordeaux 1 (2010). 
[22] J. Whitney, R. Nuismer, Stress fracture criteria for laminated composites containing stress concentrations, Journal of Composite Materials 8 (1974) 253-265.

[23] A. Hillerborg, M. Modéer, P.-E. Petersson, Analysis of crack formation and crack growth in concrete by means of fracture mechanics and finite elements, Cement and Concrete Research 6 (6) (1976) 773-781.

[24] P. Robinson, U. Galvanetto, D. Tumino, G. Bellucci, D. Violeau, Numerical simulation of fatigue-driven delamination using interface elements, Int. J. Numer. Meth. Engng. 63 (2005) 1824-1848.

[25] S. Hallett, B. Green, W. Jiang, M. Wisnom, An experimental and numerical investigation into the damage mechanisms in notched composites, Composites Part A : Applied Science and Manufacturing 40 (5) (2009) $613-624$.

[26] A. Rogani, P. Navarro, S. Marguet, J.-F. Ferrero, C. Lanouette, Tensile post-impact behaviour of thin carbon/epoxy and glass/epoxy hybrid woven laminates - part ii: Numerical study, Composite Structures 230 (2019).

[27] A. Rogani, P. Navarro, S. Marguet, J.-F. Ferrero, C. Lanouette, Tensile post-impact behaviour of thin carbon/epoxy and glass/epoxy hybrid woven laminates - part i: Experimental study, Composite Structures 230 (2019).

[28] S. D. Pandita, G. Huysmans, M. Wevers, I. Verpoest, Tensile fatigue behaviour of glass plain-weave fabric composites in on- and off-axis direc- 
tions, Composites Part A : Applied Science and Manufacturing 32 (10) (2001) $1533-1539$.

[29] P. Navarro, F. Pascal, J. Aubry, S. Marguet, J.-F. Ferrero, S. Lemaire, Rauch, Semi-continuous approach for the study of impacts on woven composite laminates: Modeling interlaminar behavior with a specific interface element, International Journal of Impact Engineering 75 (2015) $184-193$.

[30] F. Pascal, P. Navarro, S. Marguet, Ferrero, On the modelling of low to medium velocity impact onto woven composite materials with a $2 \mathrm{~d}$ semi-continuous approach, Composite Structures 134 (2015) $302-310$.

[31] F. Pascal, O. Dorival, P. Navarro, S. Marguet, J.-F. Ferrero, Impact damage prediction in thin woven composite laminates - part i: Modeling strategy and validation, Composite Structures 190 (2018) $32-42$.

[32] F. Pascal, A. Rogani, B. Mahmoud, P. Navarro, S. Marguet, Ferrero, Impact damage prediction in thin woven composite laminates - part ii: Application to normal and oblique impacts on sandwich structure, Composite Structures 190 (2018) 43 - 51. 


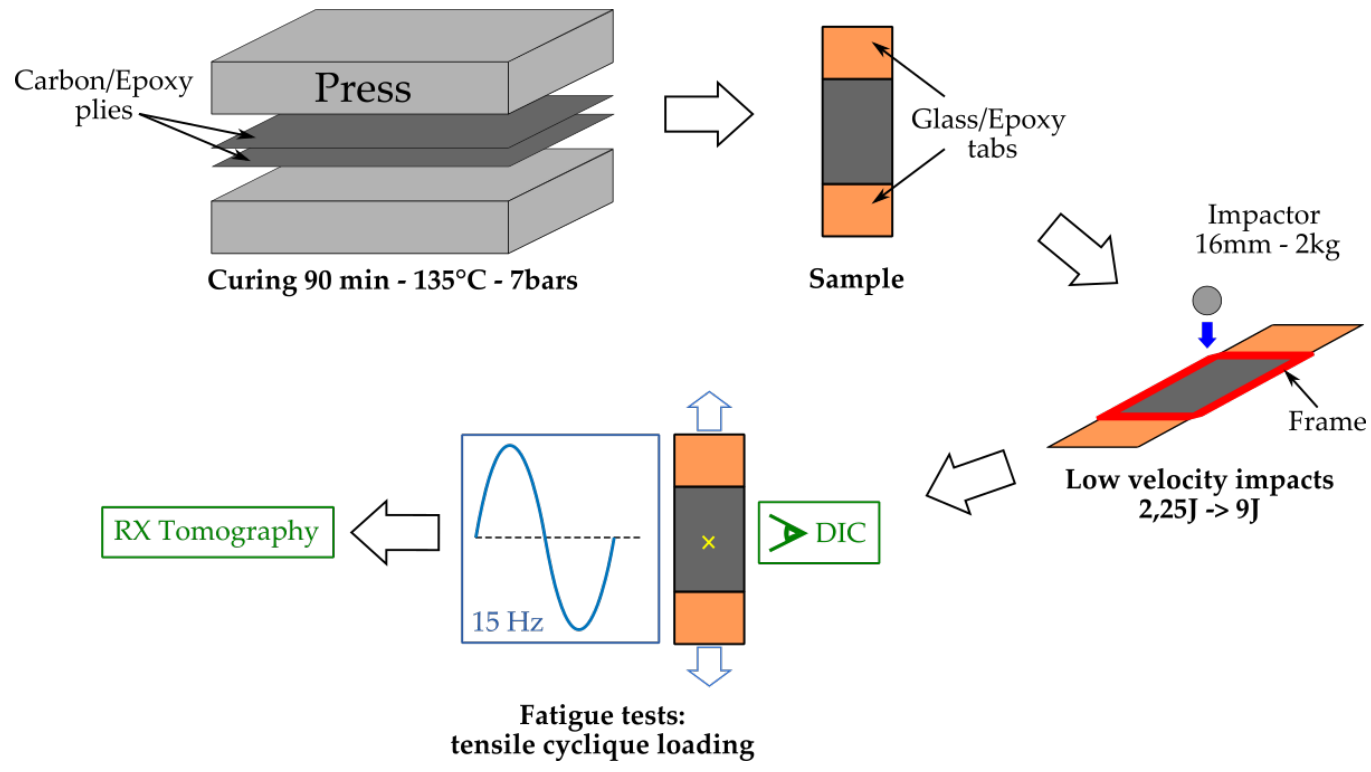

Figure 1: Experimental path diagram

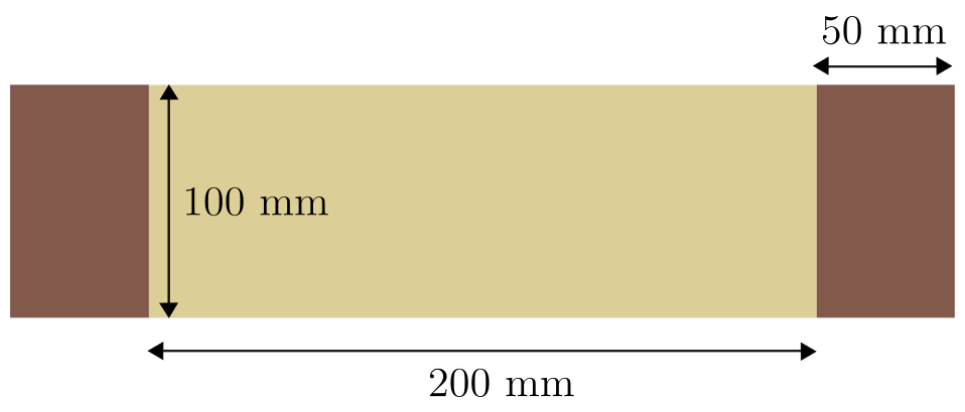

Figure 2: Sample geometry 


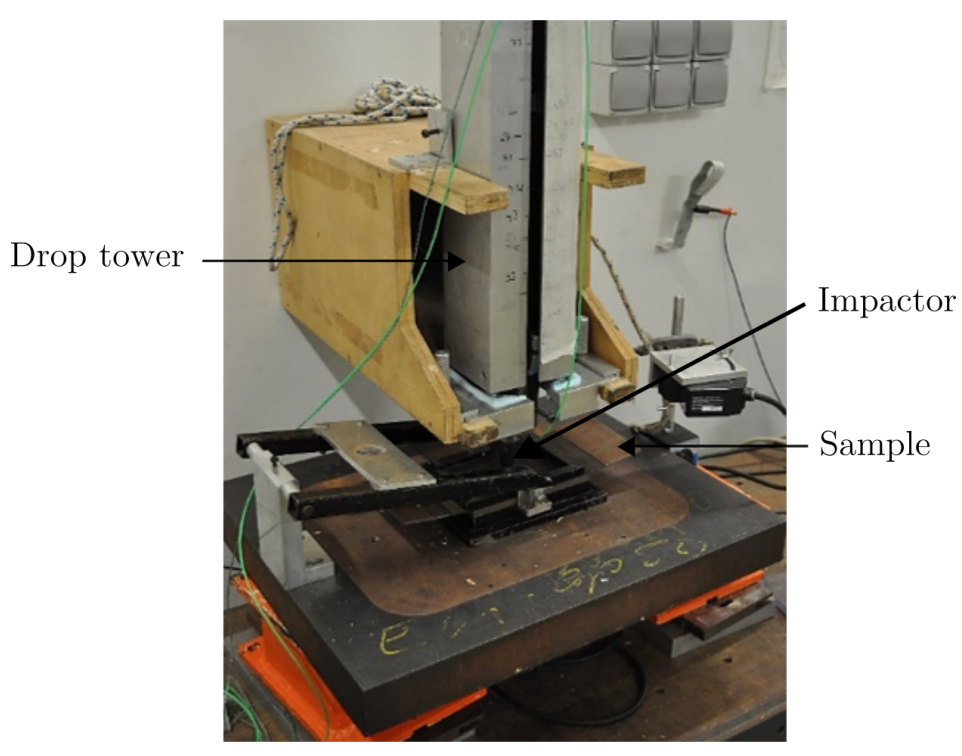

Figure 3: Drop weight impact test [27]

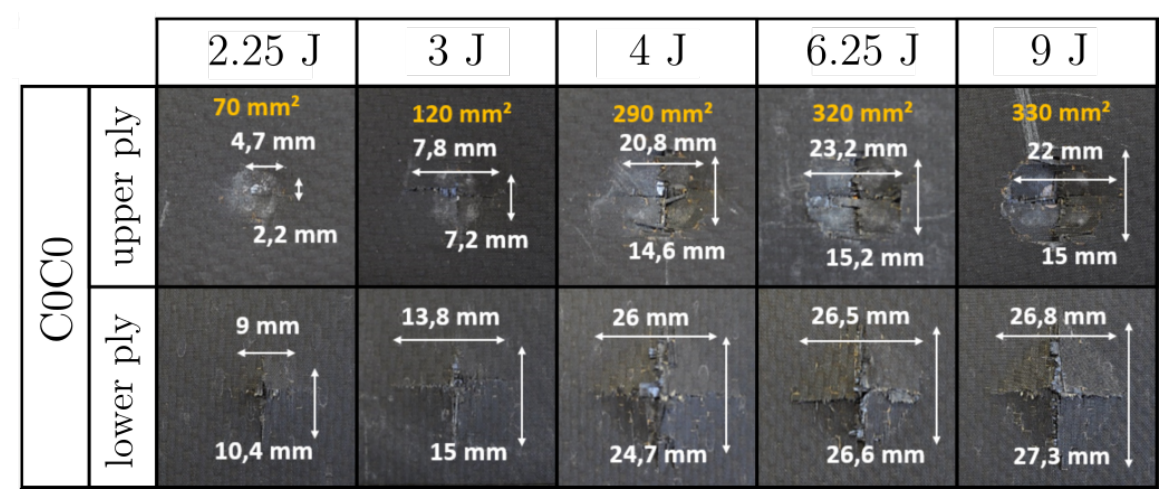

Figure 4: Post-impact fracture surfaces on $\mathrm{C} 0 \mathrm{C} 0$ samples [27] 


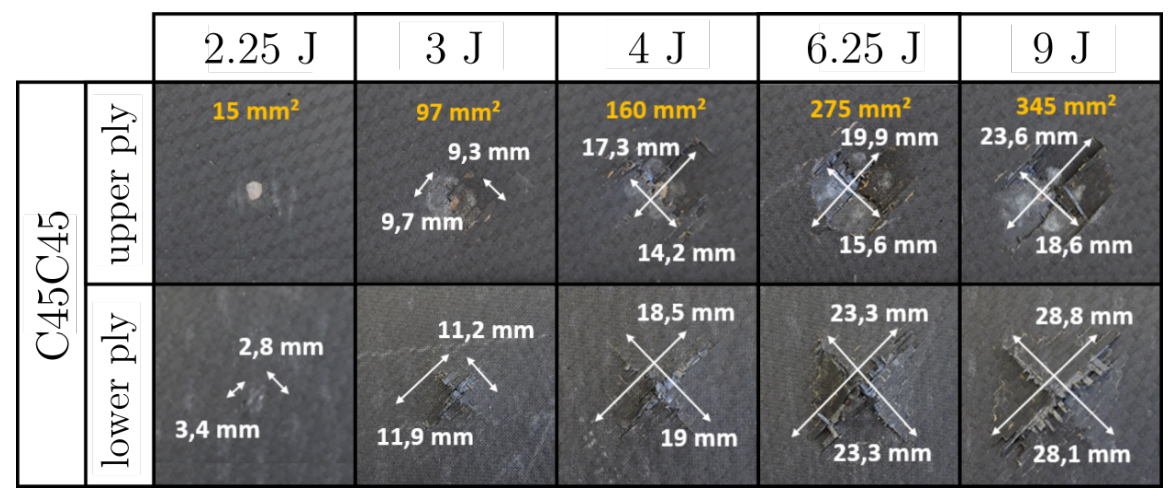

Figure 5: Post-impact fracture surfaces on C45C45 samples [27]

\begin{tabular}{|c|c|c|c|c|c|c|}
\hline & $2.25 \mathrm{~J}$ & $3 \mathrm{~J}$ & $4 \mathrm{~J}$ & $6.25 \mathrm{~J}$ & $9 \mathrm{~J}$ \\
\hline \multirow{4}{*}{$\begin{array}{l}0 \\
20 \\
7 \\
0\end{array}$} & 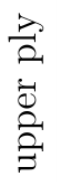 & ${ }_{4,7 \mathrm{~mm}}^{100 \mathrm{~mm}^{2}}$ & $\frac{180 \mathrm{~mm}^{2}}{6,1 \mathrm{~mm}}$ & $\begin{array}{c}255 \mathrm{~mm}^{2} \\
15,6 \mathrm{~mm} \\
14,6 \mathrm{~mm}\end{array}$ & $\underset{15,6 \mathrm{~mm}}{230 \mathrm{~mm}^{2}}$ & $15,5 \mathrm{~mm}$ \\
\hline & $\lambda$ & $11,1 \mathrm{~mm}$ & $15,7 \mathrm{~mm}$ & $23,2 \mathrm{~mm}$ & $23,4 \mathrm{~mm}$ & $24,5 \mathrm{~mm}$ \\
\hline & $\dot{2}$ & 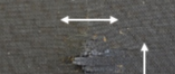 & & & $\stackrel{3}{\longrightarrow}$ & 4 \\
\hline & $\underline{0}$ & $9,4 \mathrm{~mm}$ & $15,8 \mathrm{~mm}$ & $22,6 \mathrm{~mm} \downarrow$ & $22,5 \mathrm{~mm}$ & $24,4 \mathrm{~mm}$ \\
\hline
\end{tabular}

Figure 6: Post-impact fracture surfaces on $\mathrm{C} 45 \mathrm{C} 0$ samples [27]

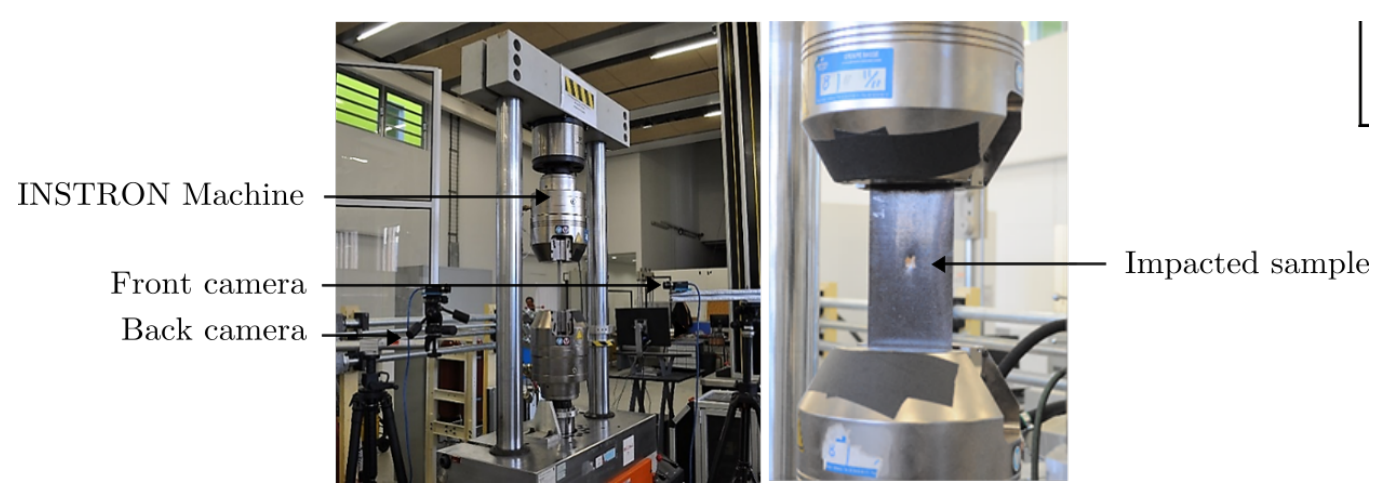

Figure 7: Fatigue tensile test on impacted sample 


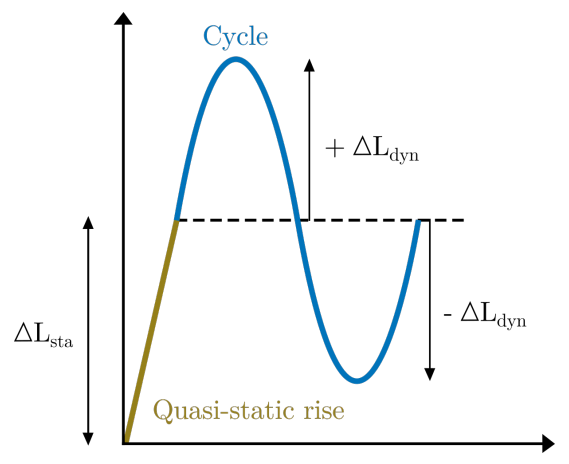

Figure 8: Cycle of fatigue 

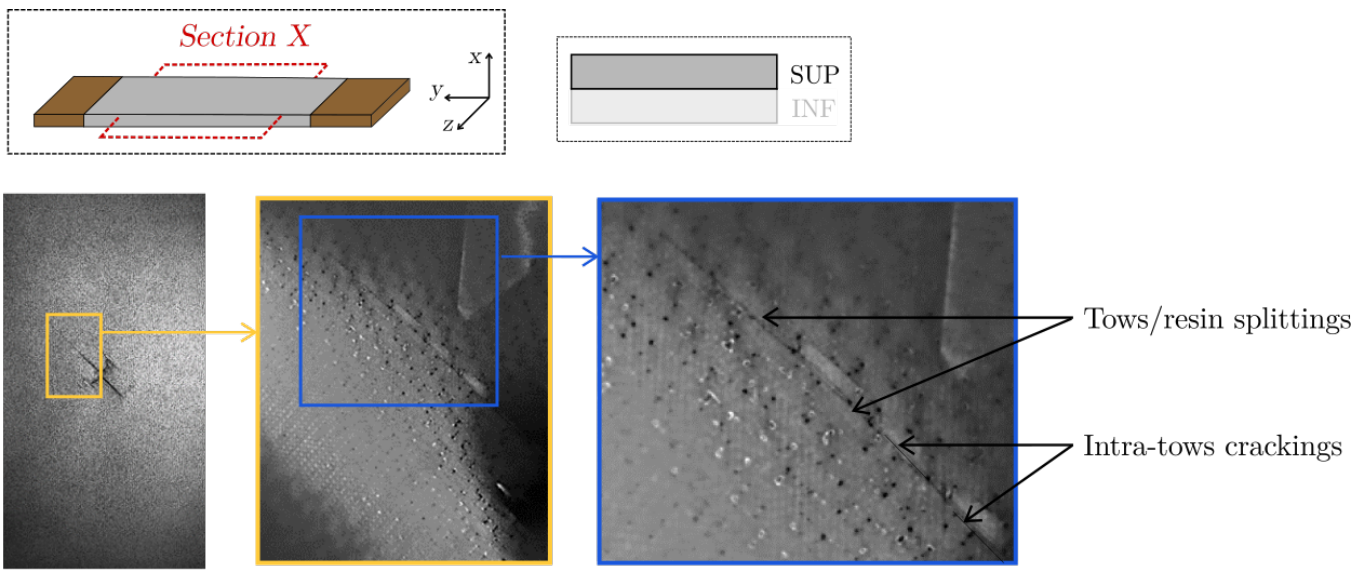

Digital Image Correlation (DIC)

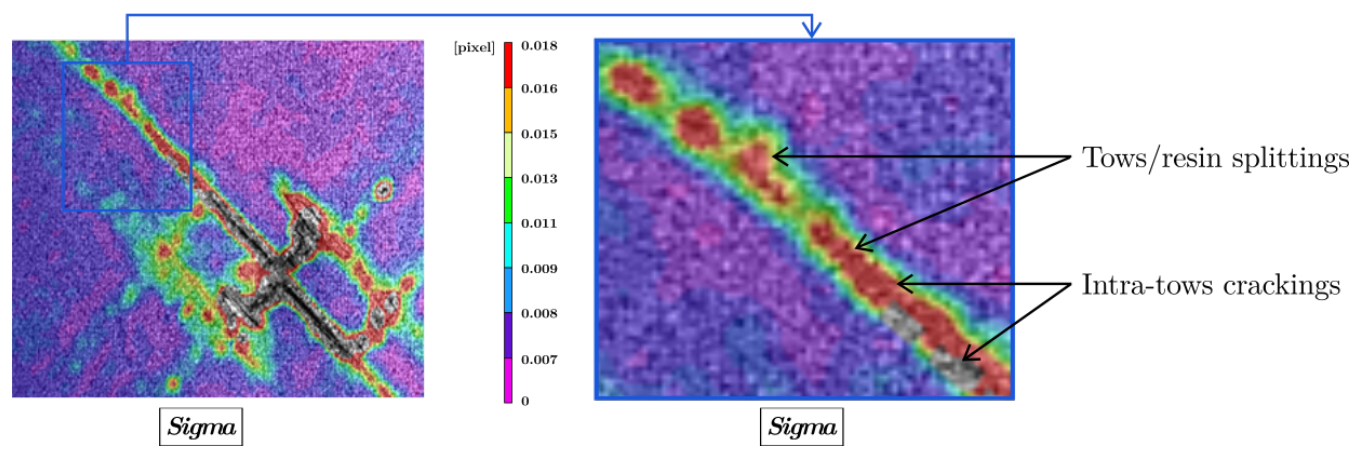

Figure 9: Parallel between the quality factor Sigma and the type of damaging which occurs during a fatigue tensile test on an impacted carbon woven laminate (example for C45C45 sample) 


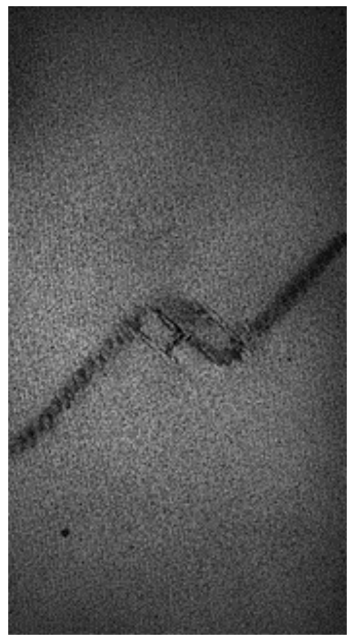

Figure 10: Fracture surfaces obtained after fatigue tensile test on impacted carbon woven laminate of configuration $\mathrm{C} 45 \mathrm{C} 45$ 


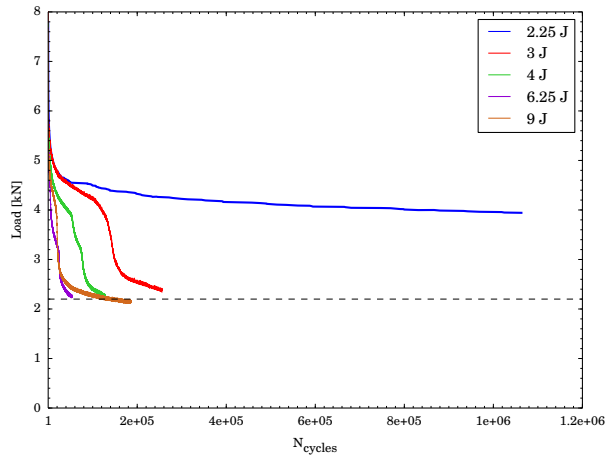

(a) Influence of impact energy

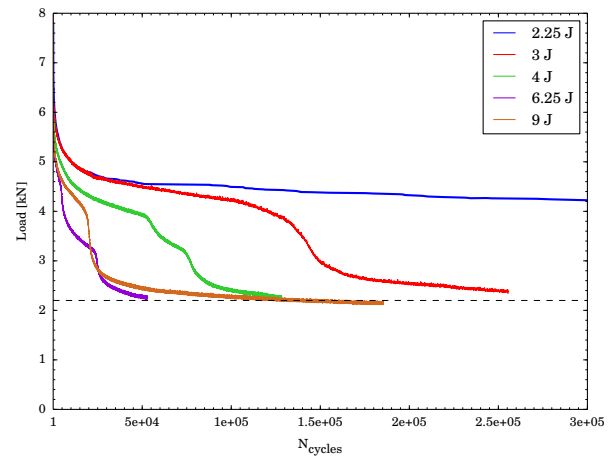

(Zoom)

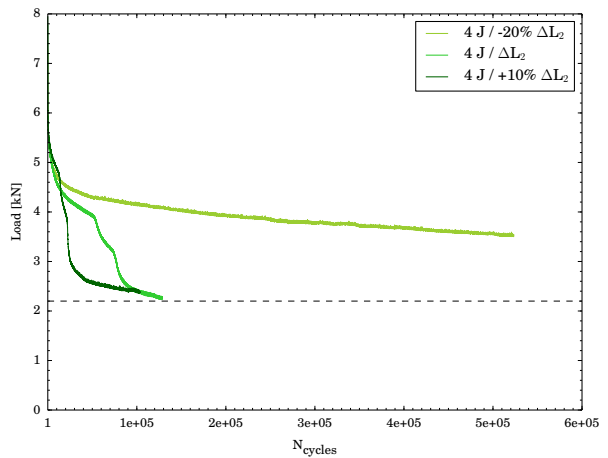

(b) Influence of displacement level

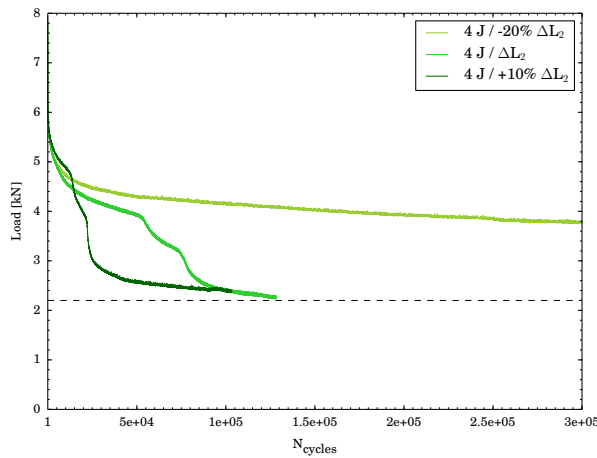

(Zoom)

Figure 11: Load evolution depending on the number of cycles for the configuration $\mathrm{C} 45 \mathrm{C} 45$ 


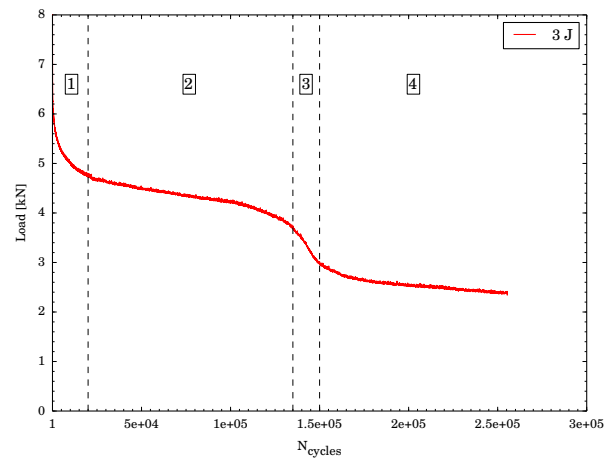

Figure 12: Steps of load evolution depending on the number of cycles for the configuration $\mathrm{C} 45 \mathrm{C} 45$ - Example on a sample initially impacted with an energy of $3 \mathrm{~J}$

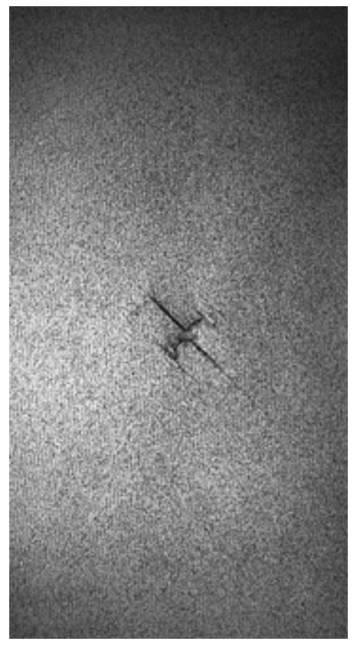

Figure 13: Fracture surfaces obtained after fatigue tensile test on impacted carbon woven laminate of configuration $\mathrm{C} 45 \mathrm{C} 45$ with the lower impact energy and displacement level 


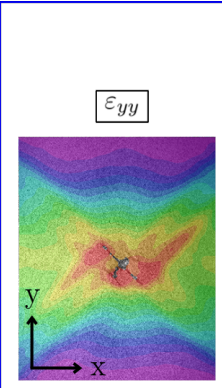

Testing start

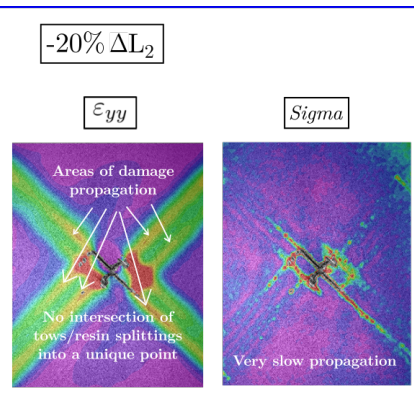

500000 cycles

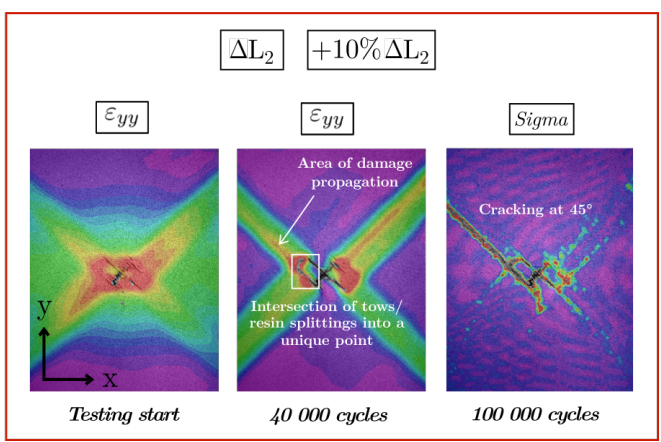

Figure 14: Areas of the damage propagation during the post-impact fatigue loading on the configuration $\mathrm{C} 45 \mathrm{C} 45$

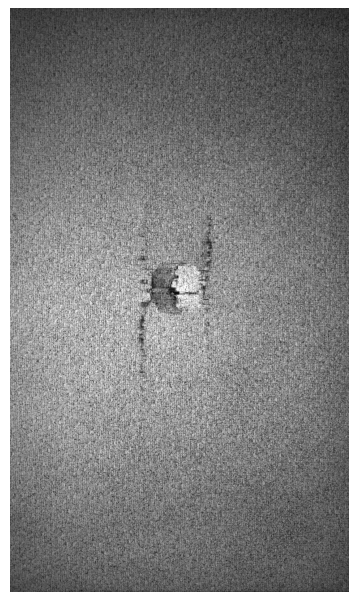

Figure 15: Fracture surfaces obtained after fatigue tensile test on impacted carbon woven laminate of configuration $\mathrm{C} 0 \mathrm{C} 0$ 


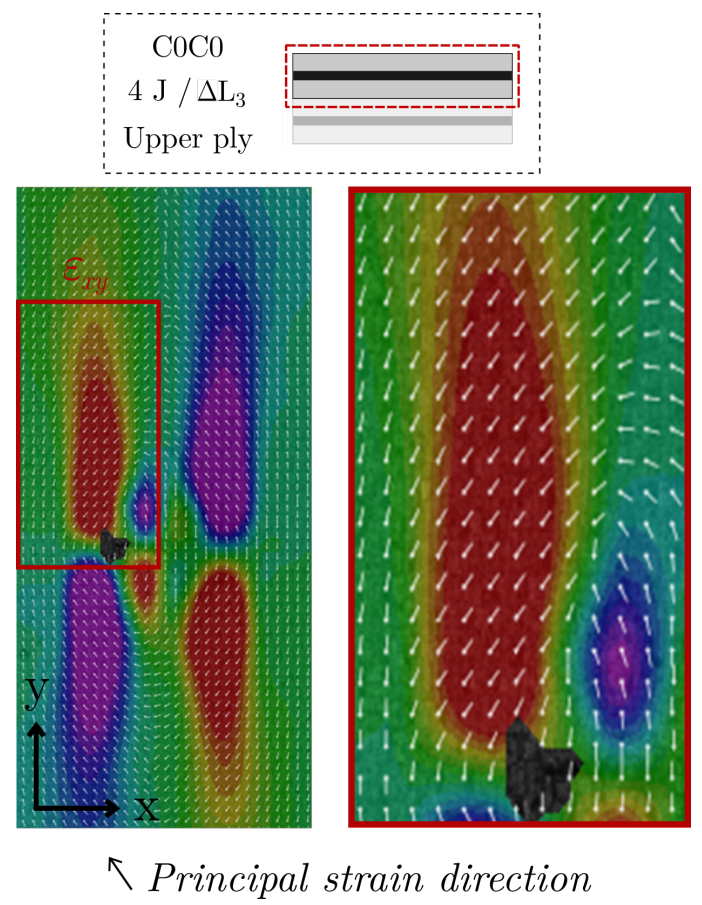

Figure 16: Strain field $\varepsilon_{x y}$ obtained during fatigue tensile test in the upper ply of an impacted carbon woven laminate of configuration $\mathrm{C} 0 \mathrm{C} 0$ 

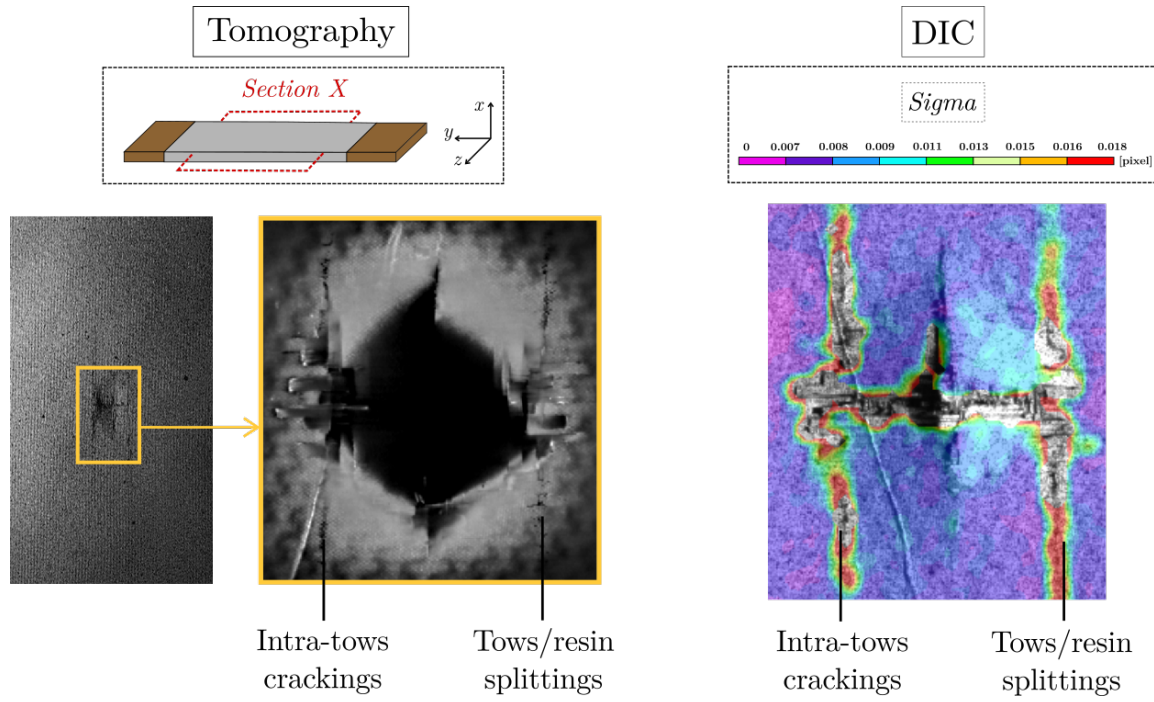

Figure 17: Damage evolution during fatigue tensile test an impacted carbon woven laminate of configuration $\mathrm{C} 0 \mathrm{C} 0$ 


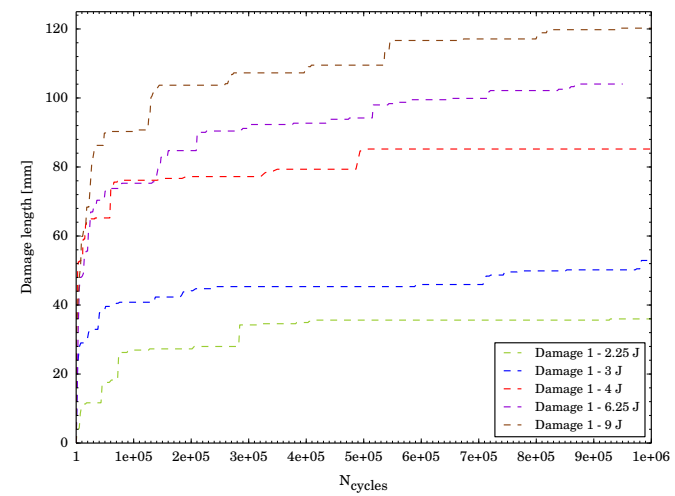

(a) Damage 1 - Influence of impact energy

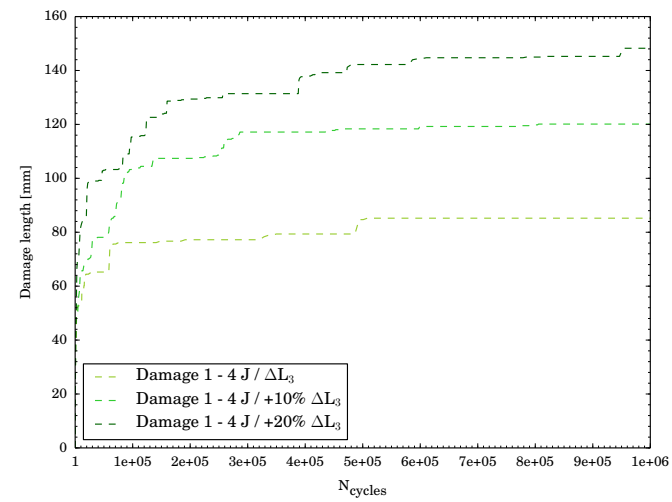

(c) Damage 1 - Influence of displacement level

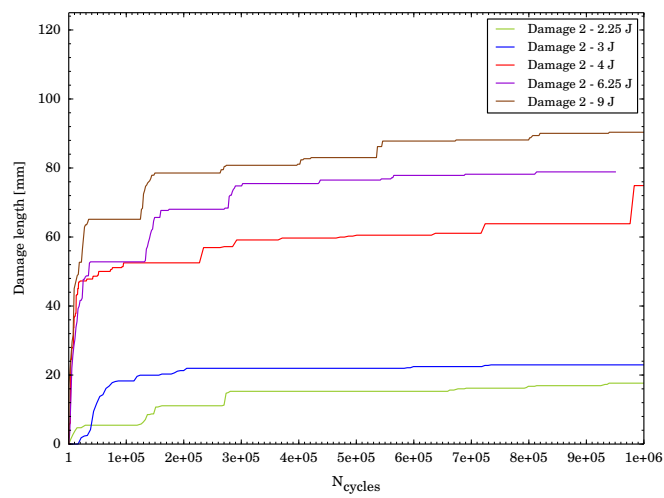

(b) Damage 2 - Influence of impact energy

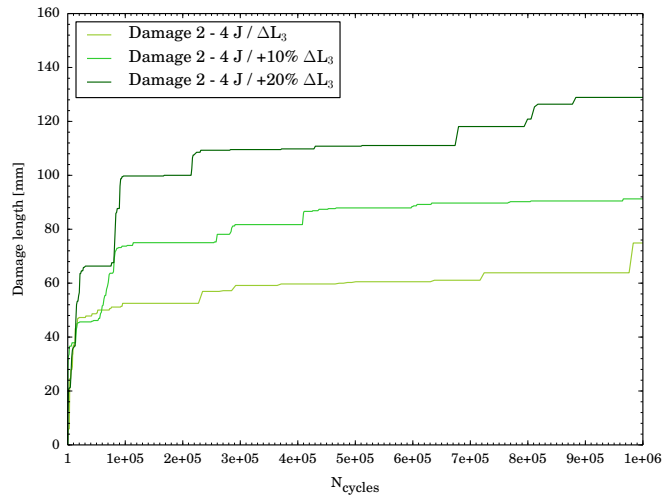

(d) Damage 2 - Influence of displacement level

Figure 18: Length evolution of the tows/resin splittings (Damage 1) and the intra-tows crackings (Damage 2) depending on the number of cycles for the configuration $\mathrm{C} 0 \mathrm{C} 0$ 


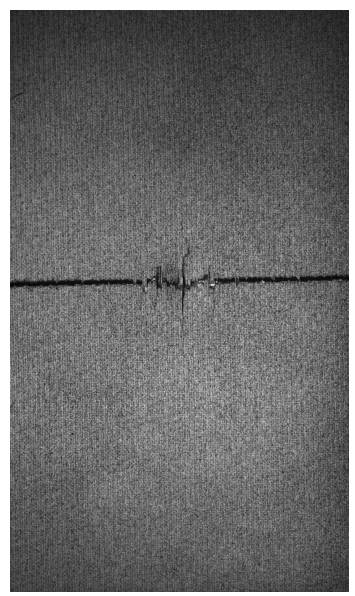

Figure 19: Fracture surfaces obtained after fatigue tensile test on impacted carbon woven laminate of configuration $\mathrm{C} 0 \mathrm{C} 0$ with the higher displacement level

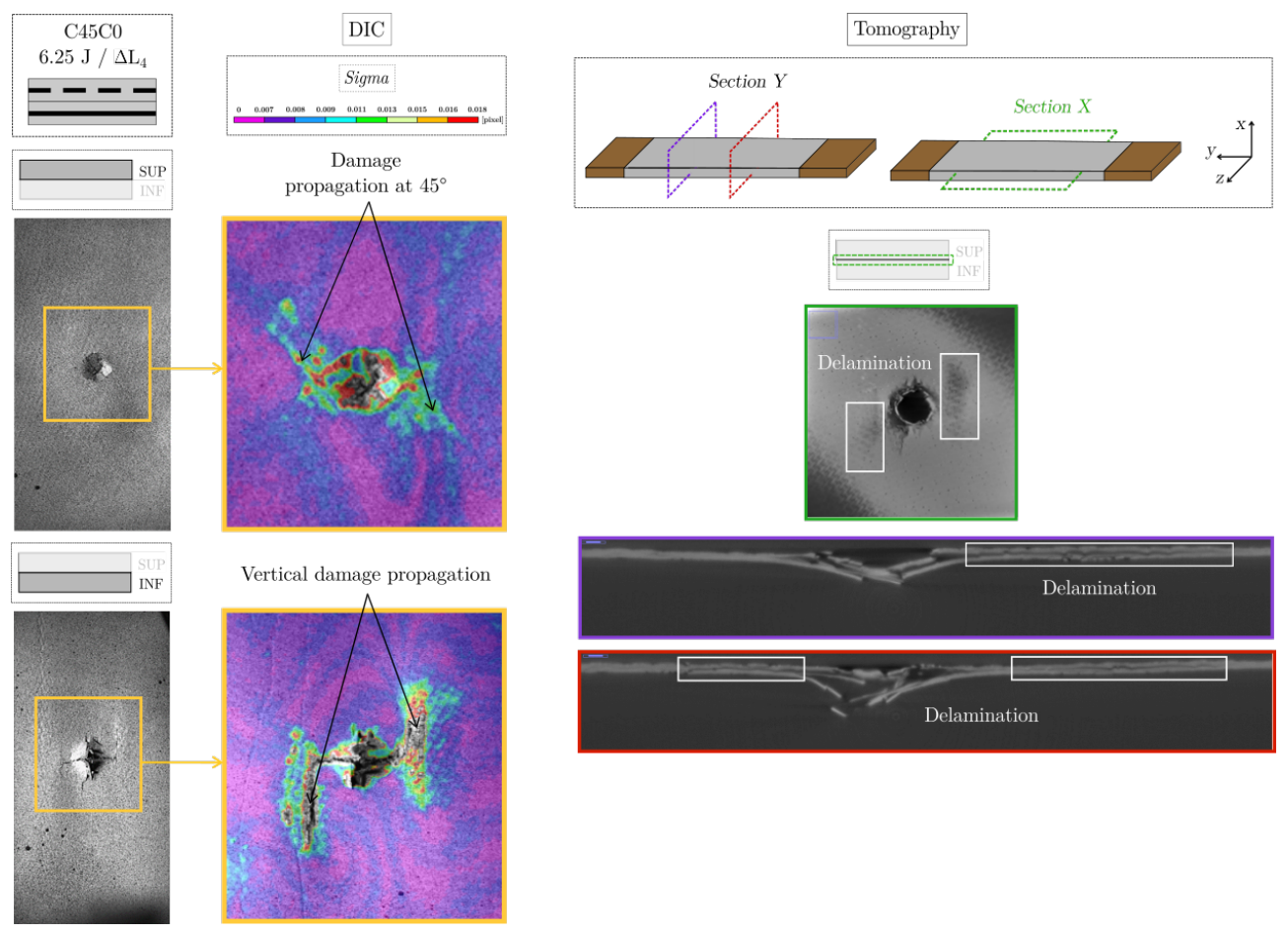

Figure 20: Progression of the post-impact damage in a sample of configuration $\mathrm{C} 45 \mathrm{C} 0$ subject to fatigue tensile loading 


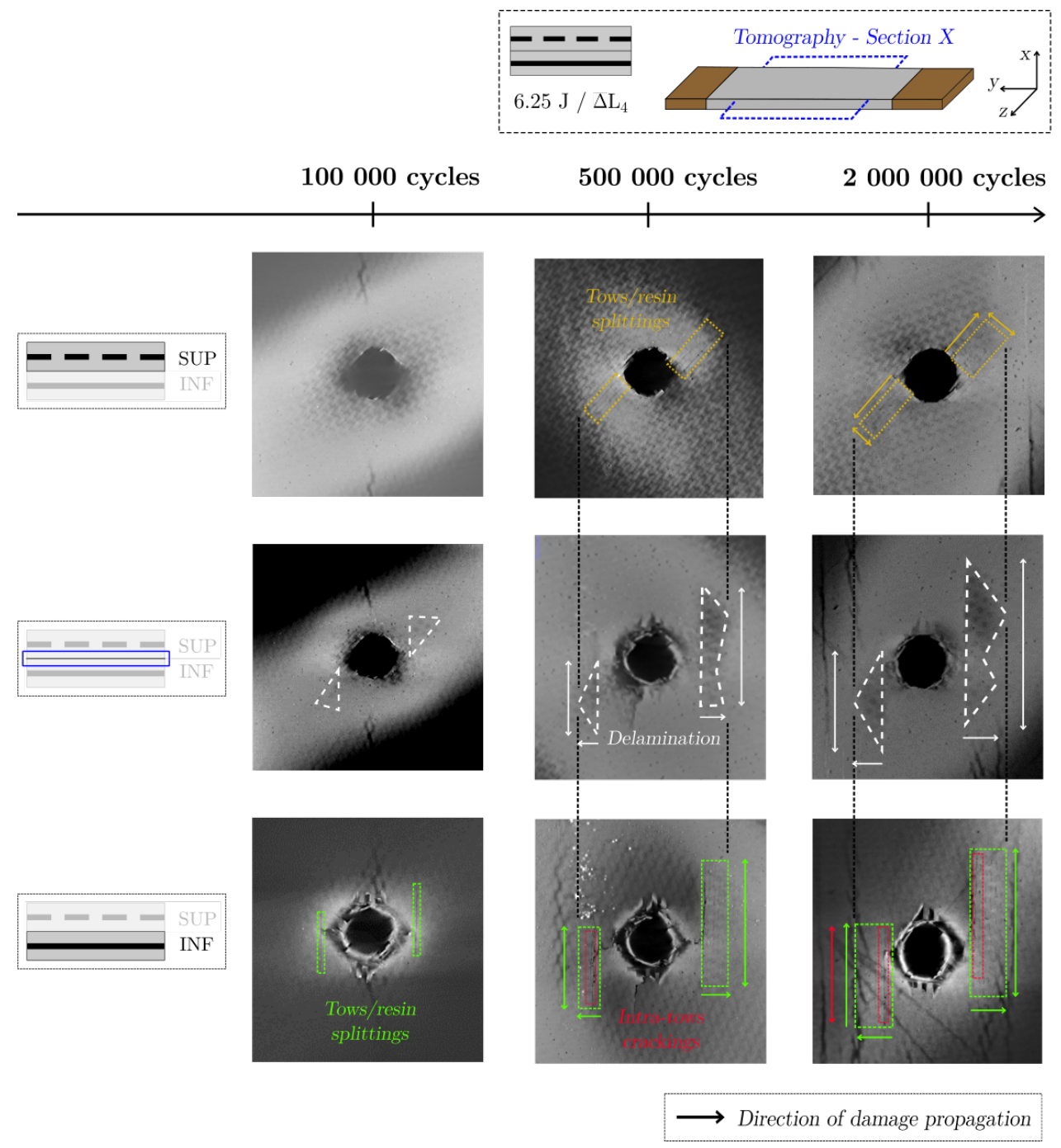

Figure 21: Scenario of post-impact damage propagation in a sample of configuration C45C0 subject to fatigue tensile loading 

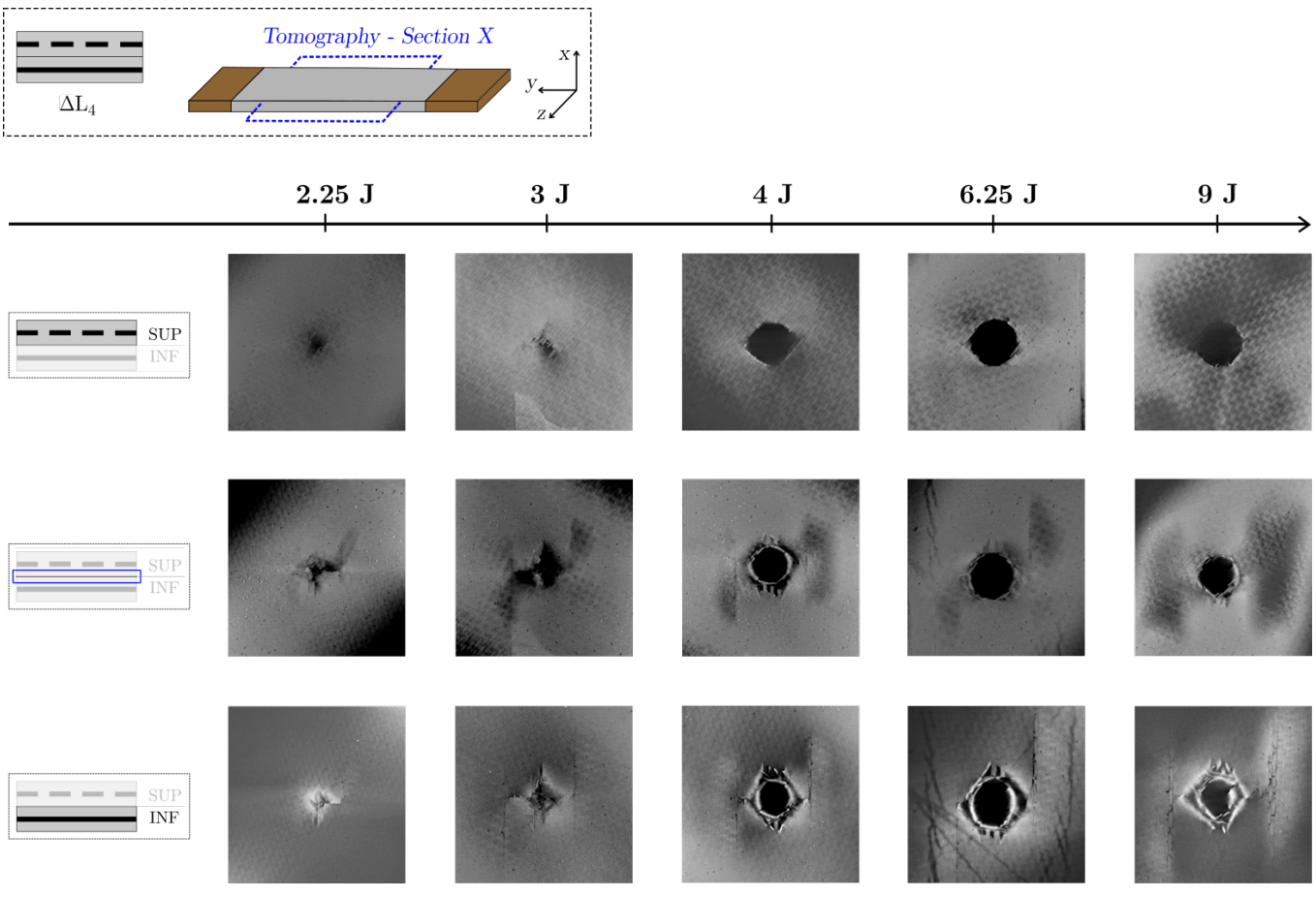

Figure 22: Damages observed in a sample of configuration $\mathrm{C} 45 \mathrm{C} 0$ after $2.10^{6}$ cycles of fatigue tensile loading
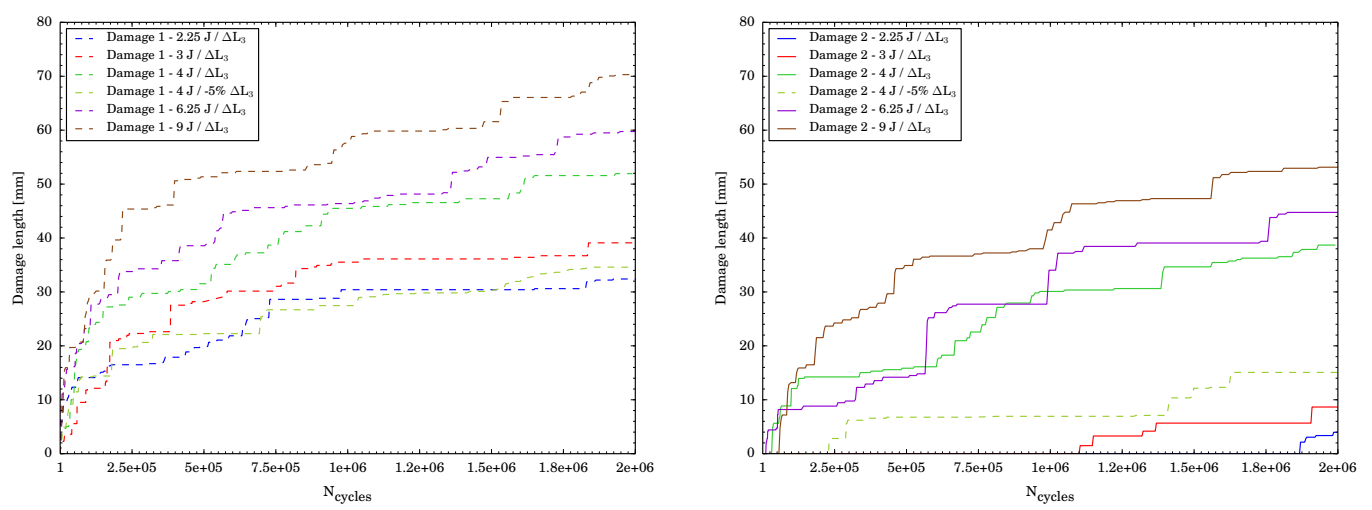

Figure 23: Length evolution of the tows/resin splittings (Damage 1) and the intra-tows crackings (Damage 2) depending on the number of cycles, the impact energy and the level of displacement in the lower ply of $\mathrm{C} 45 \mathrm{C} 0$ 


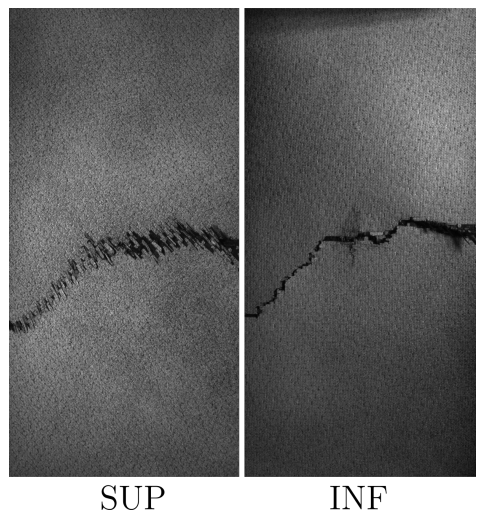

Figure 24: Fracture surface obtained after 20 fatigue cycles on an impacted sample of configuration $\mathrm{C} 45 \mathrm{C} 0$ subject to the higher displacement level

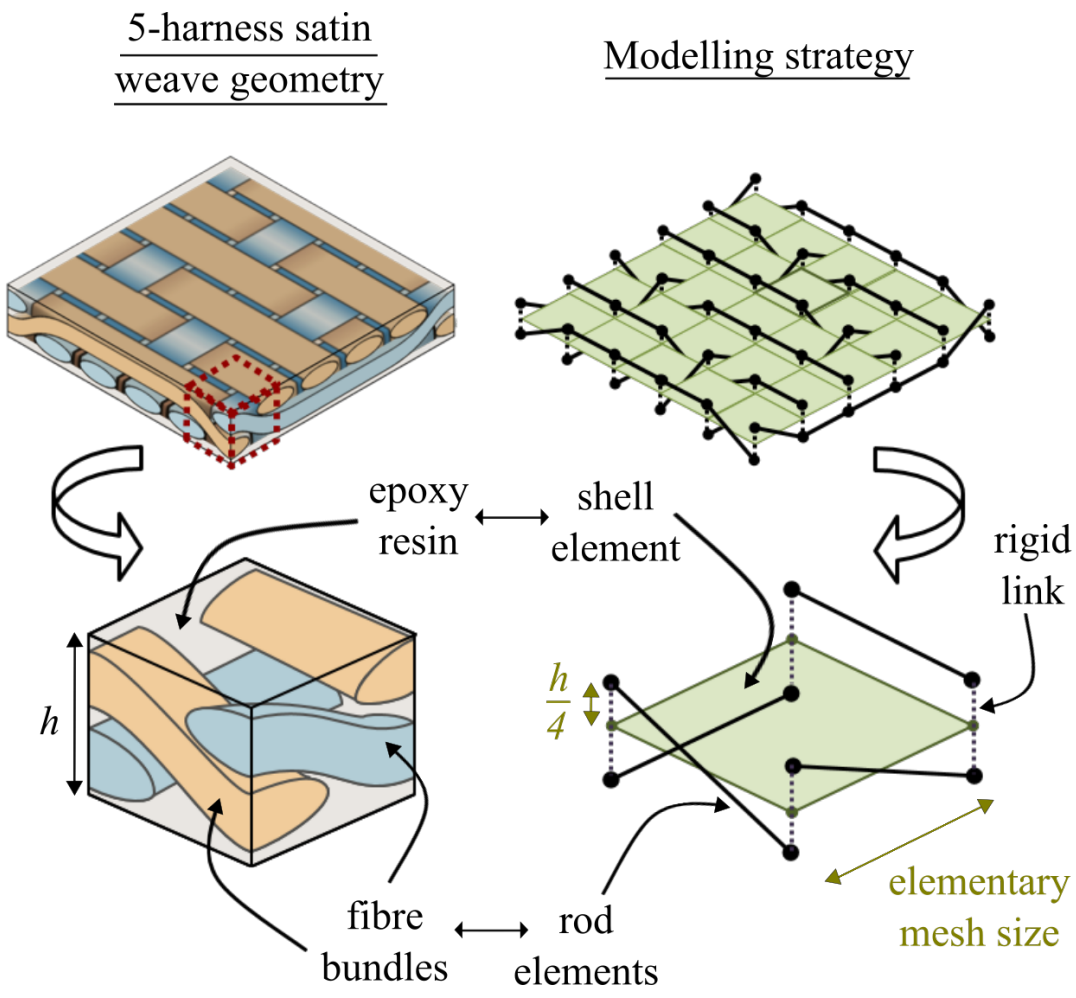

Figure 25: Modelling strategy of the woven ply 


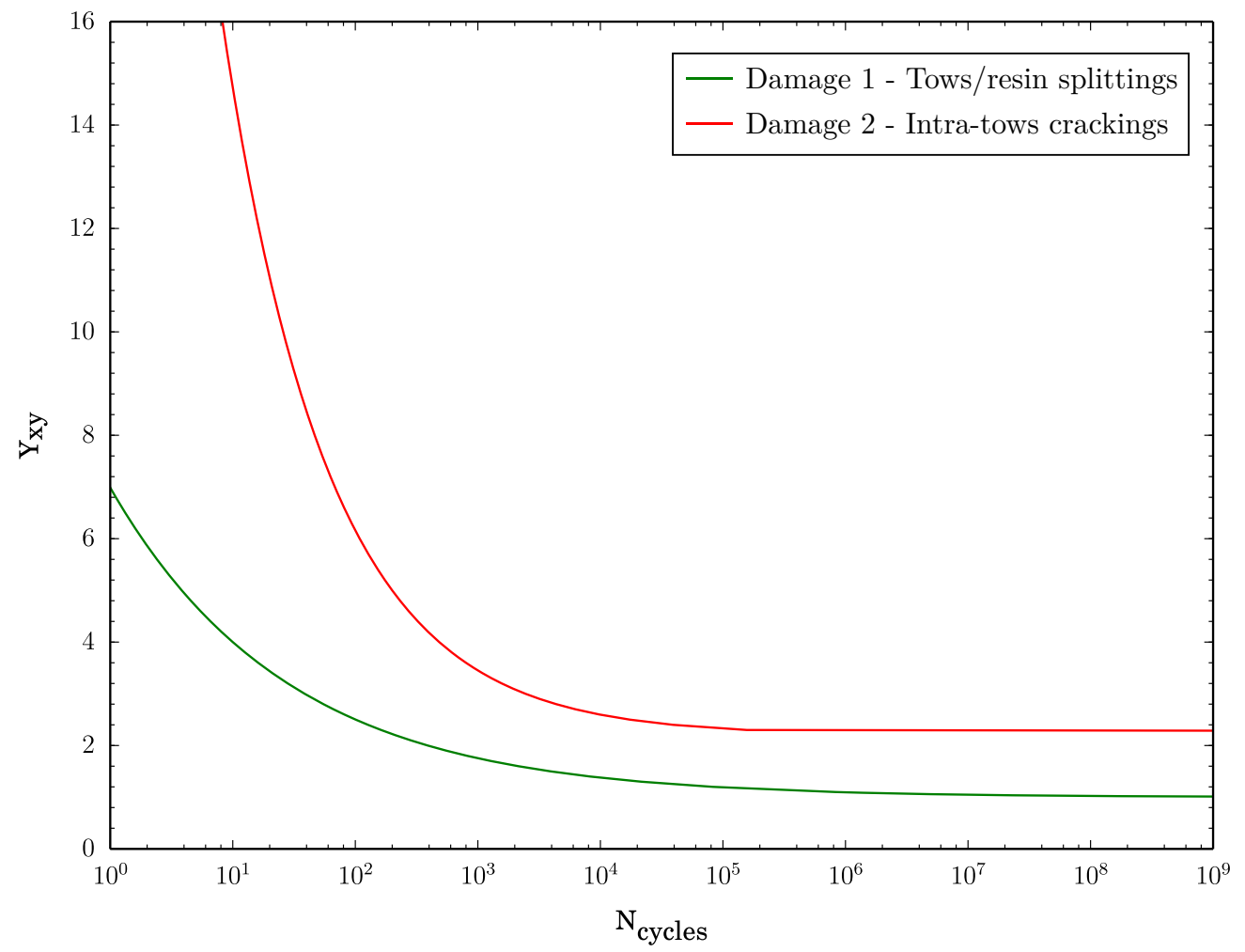

Figure 26: Resin damaging laws identified with fatigue simulations on impacted samples of configuration $\mathrm{C} 45 \mathrm{C} 45$ and $\mathrm{C} 0 \mathrm{C} 0$ 


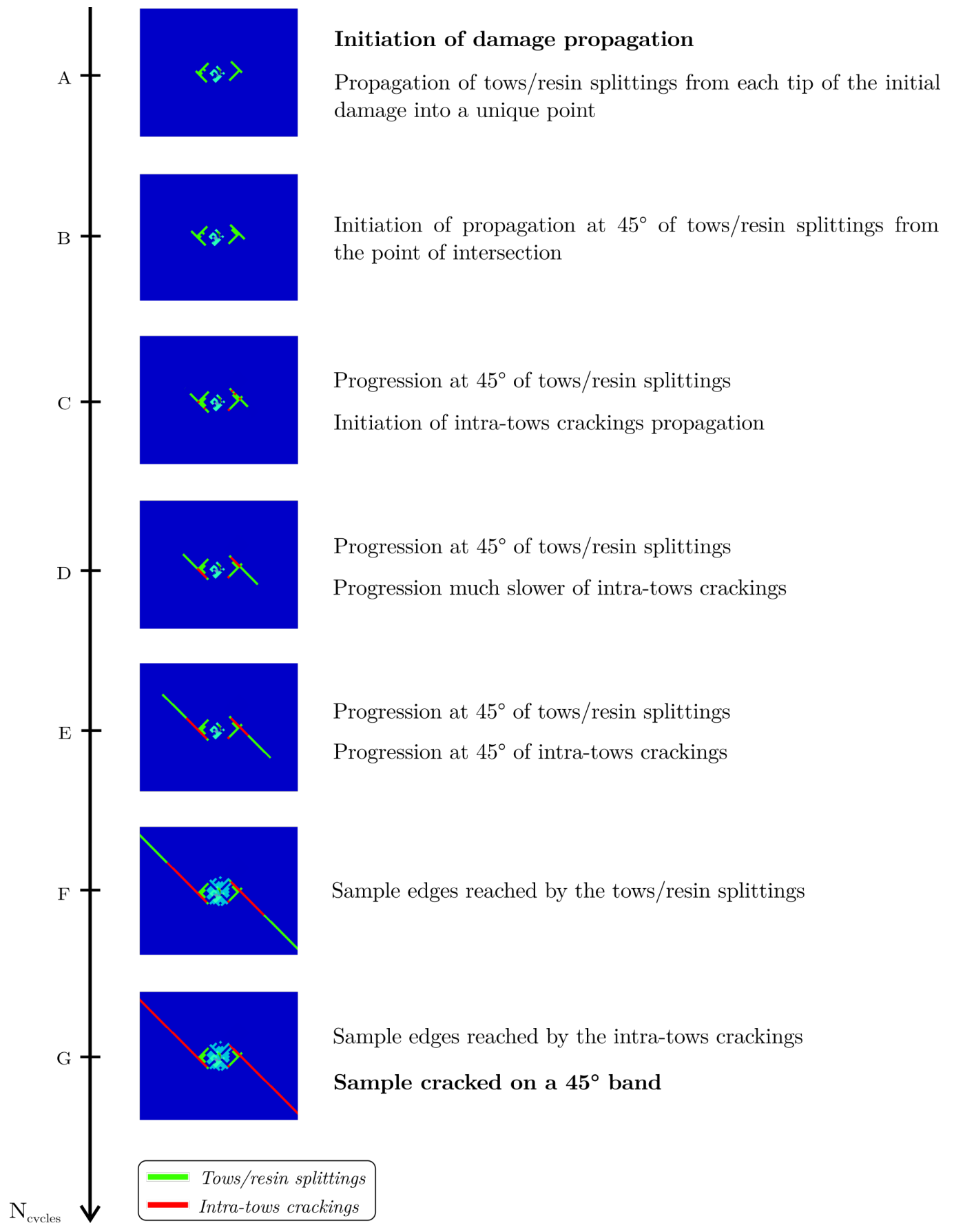

Figure 27: Post-impact damage propagation scenario numerically obtained for the configuration $\mathrm{C} 45 \mathrm{C} 45$ 


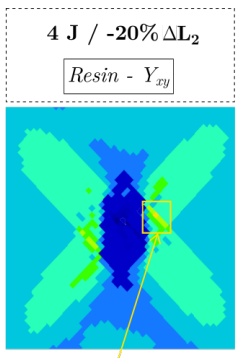

$\max =1.15$ $\sqrt{ }$
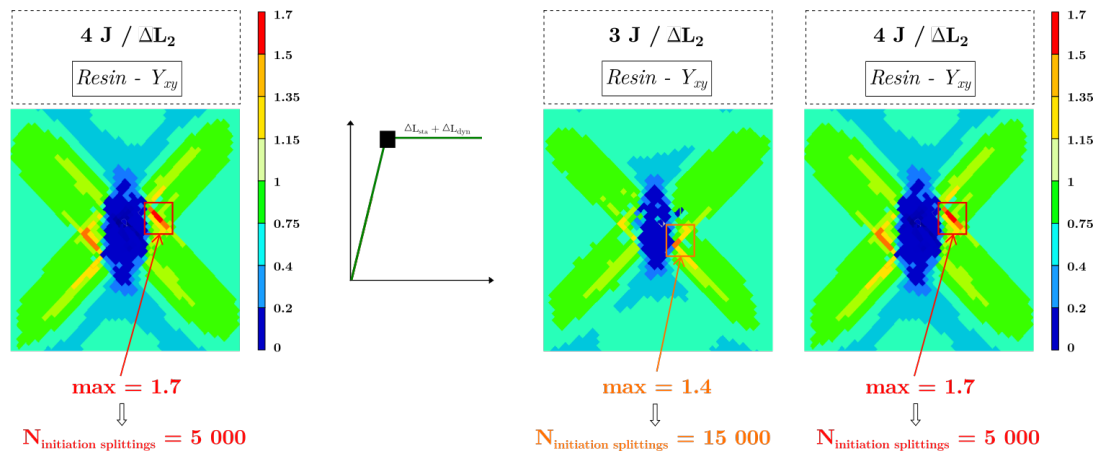

Figure 28: Energy release rate $Y_{x y}$ calculated at the end of the quasi-static rise in the resin of a laminate $\mathrm{C} 45 \mathrm{C} 45$ - Comparison between two displacement levels and two impact energies

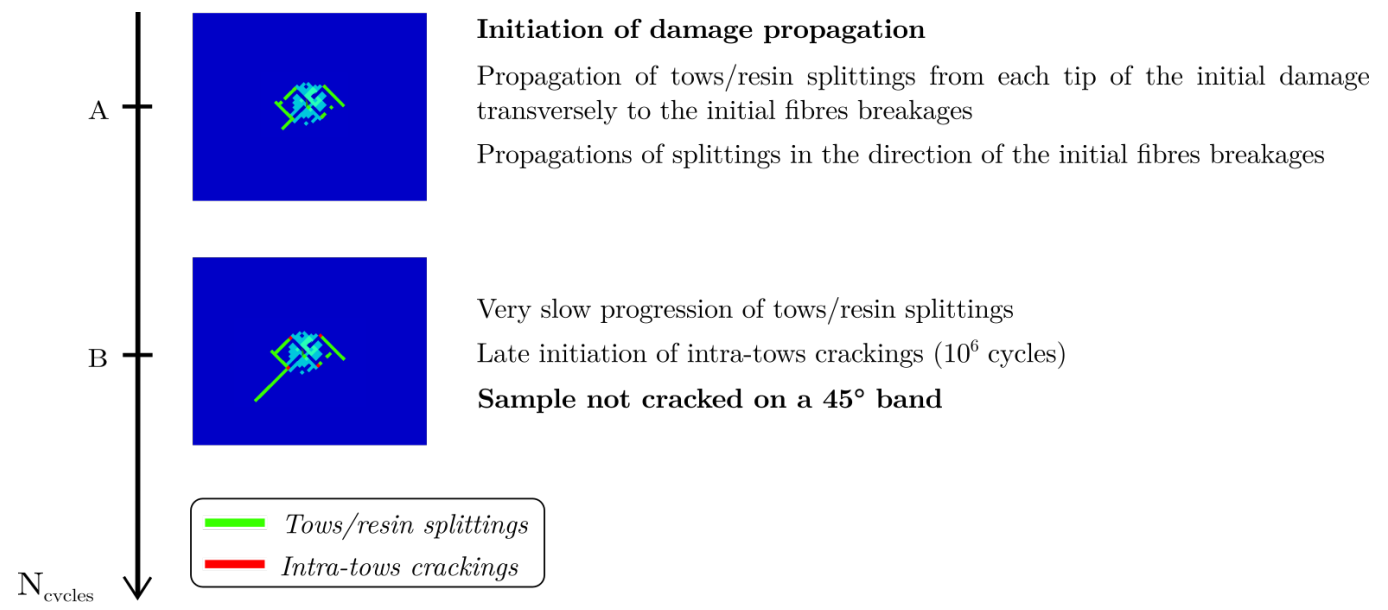

Figure 29: Post-impact damage propagation scenario numerically obtained for the configuration $\mathrm{C} 45 \mathrm{C} 45$ subject to the lower impact energy and displacement level 


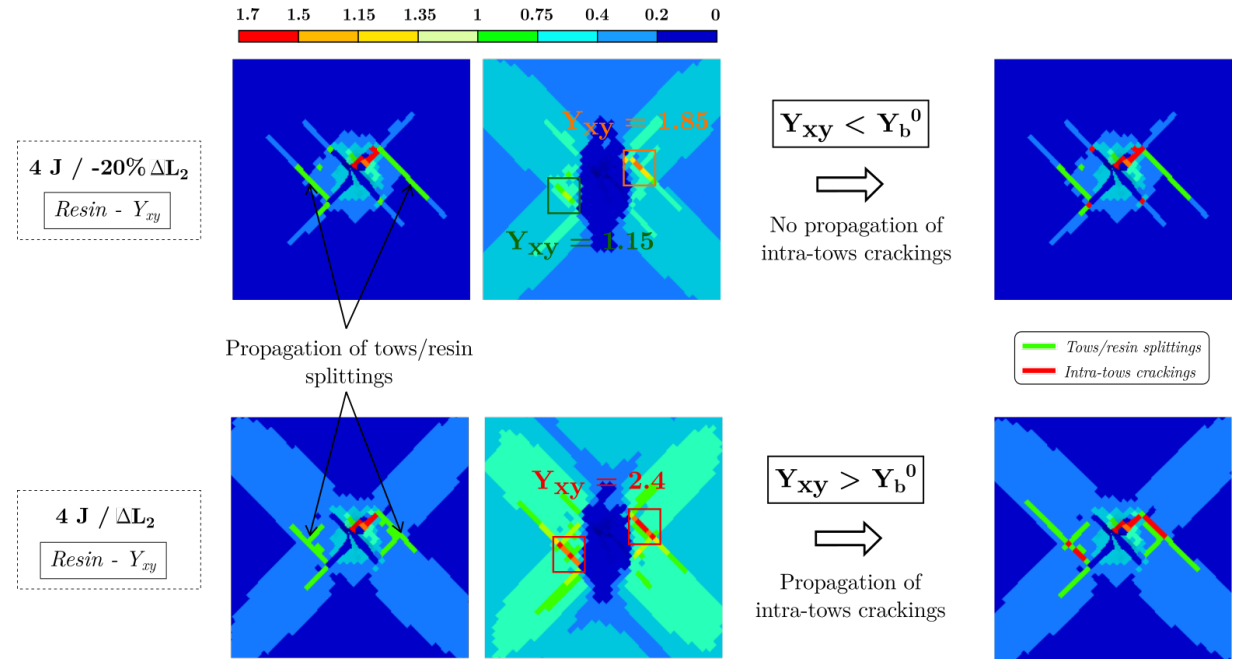

Figure 30: Intra-tows crackings propagation depending on the energy release rate $Y_{x y}$ calculated in the resin for the configuration $\mathrm{C} 45 \mathrm{C} 45$
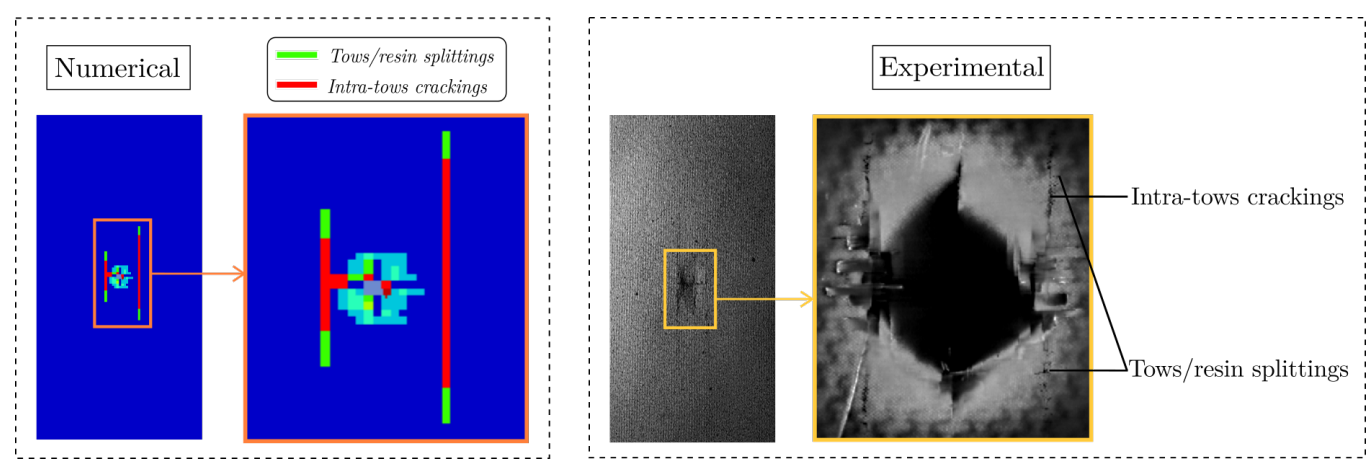

Figure 31: Post-impact damage propagation scenario for the configuration C0C0 


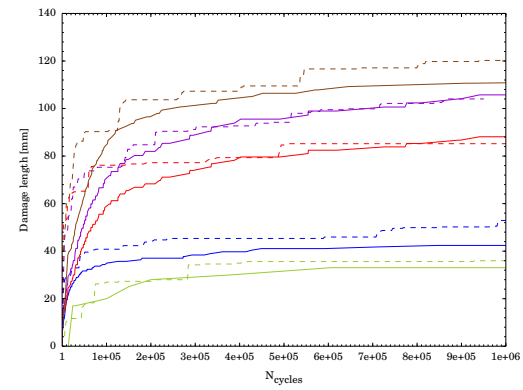

(a) Damage 1 - Influence of impact energy

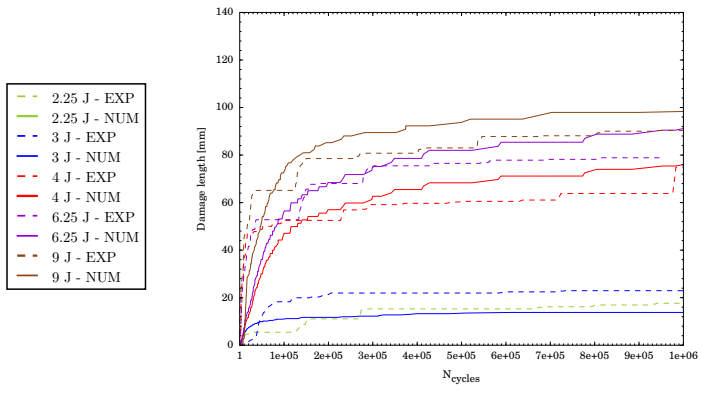

(b) Damage 2 - Influence of impact energy

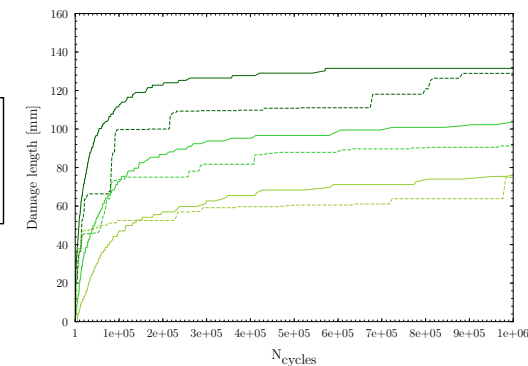

(d) Damage 2 - Influence of displacement level

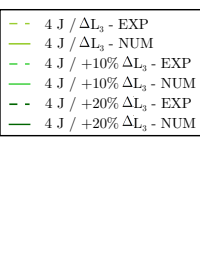

(c) Damage 1 - Influence of displacement level

Figure 32: Length evolution of the tows/resin splittings (Damage 1) and the intra-tows crackings (Damage 2) depending on the number of cycles for the configuration C0C0 Comparison numerical/experimental 


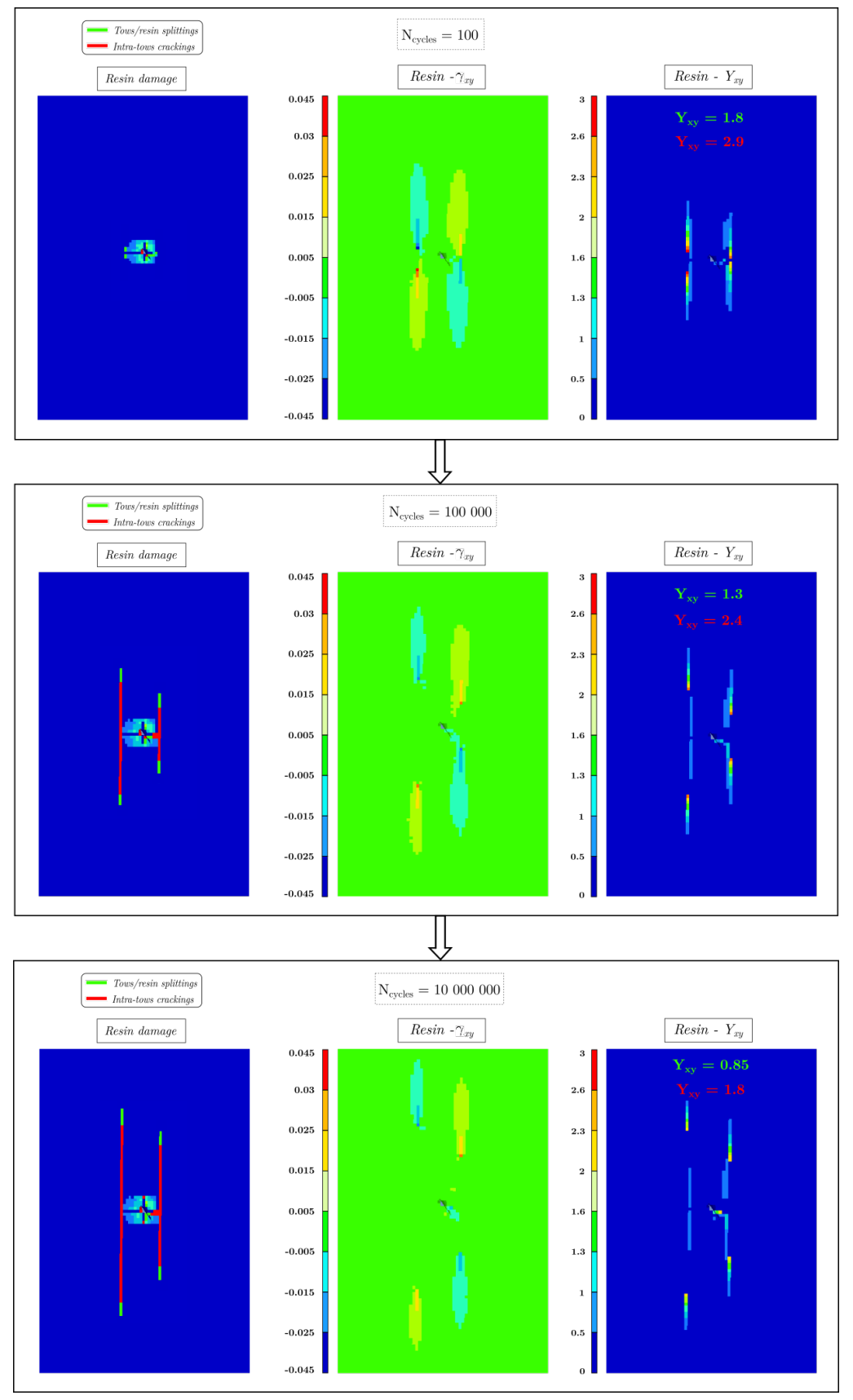

Figure 33: Decrease of the energy release rates $Y_{x y}$ calculated at the tip of the damage propagation during the fatigue simulation on the configuration $\mathrm{C} 0 \mathrm{C} 0$ 


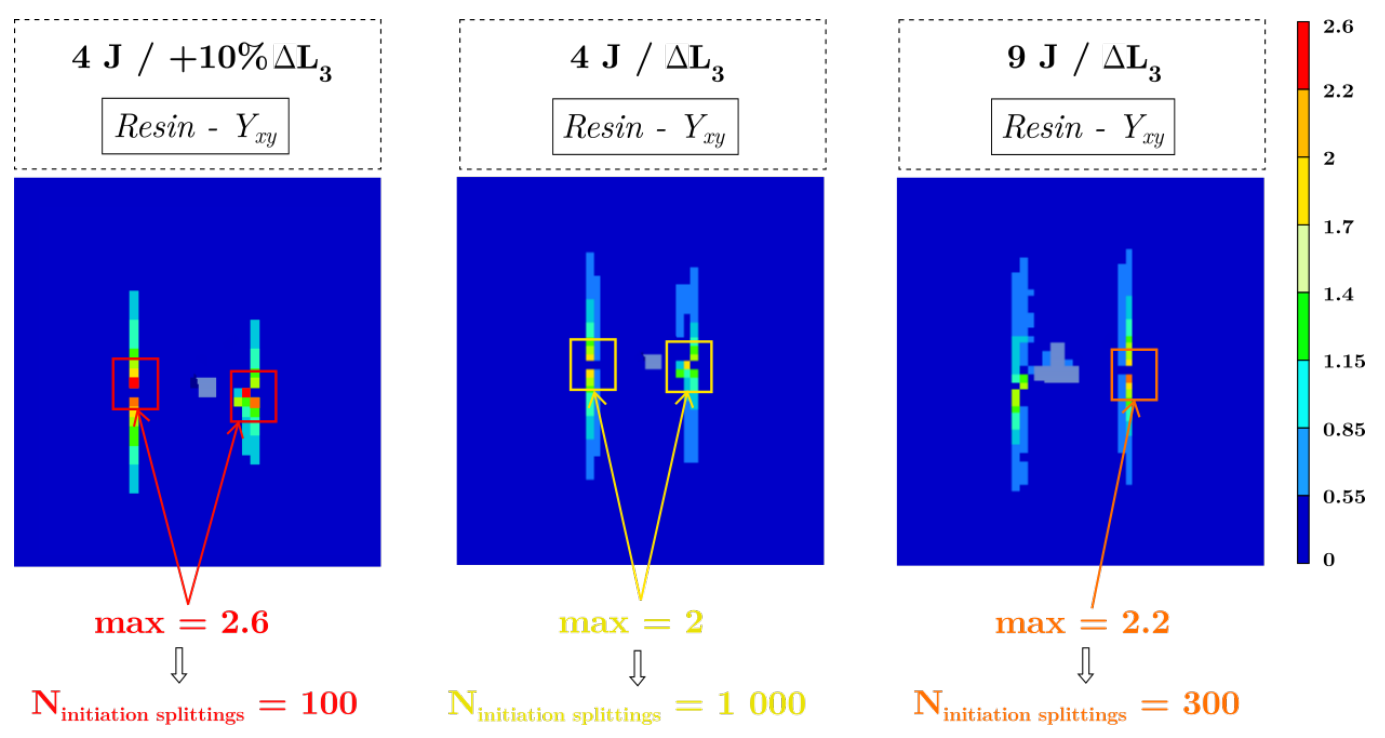

Figure 34: Number of cycles required to initiate tows/resin splittings depending on the energy release rates $Y_{x y}$ calculated in the resin at the end of the quasi-static rise for the configuration $\mathrm{C} 0 \mathrm{C} 0$

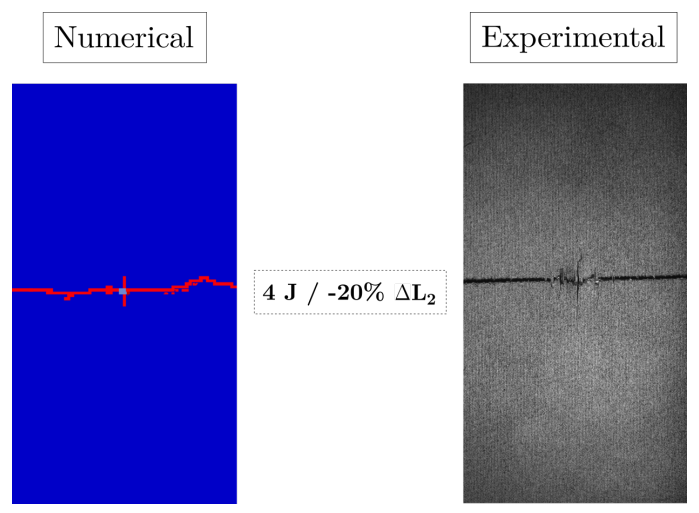

Figure 35: Post-impact damage propagation scenario for the configuration $\mathrm{C} 0 \mathrm{C} 0$ for the highest displacement level $+30 \% \Delta \mathrm{L}_{3}$ 


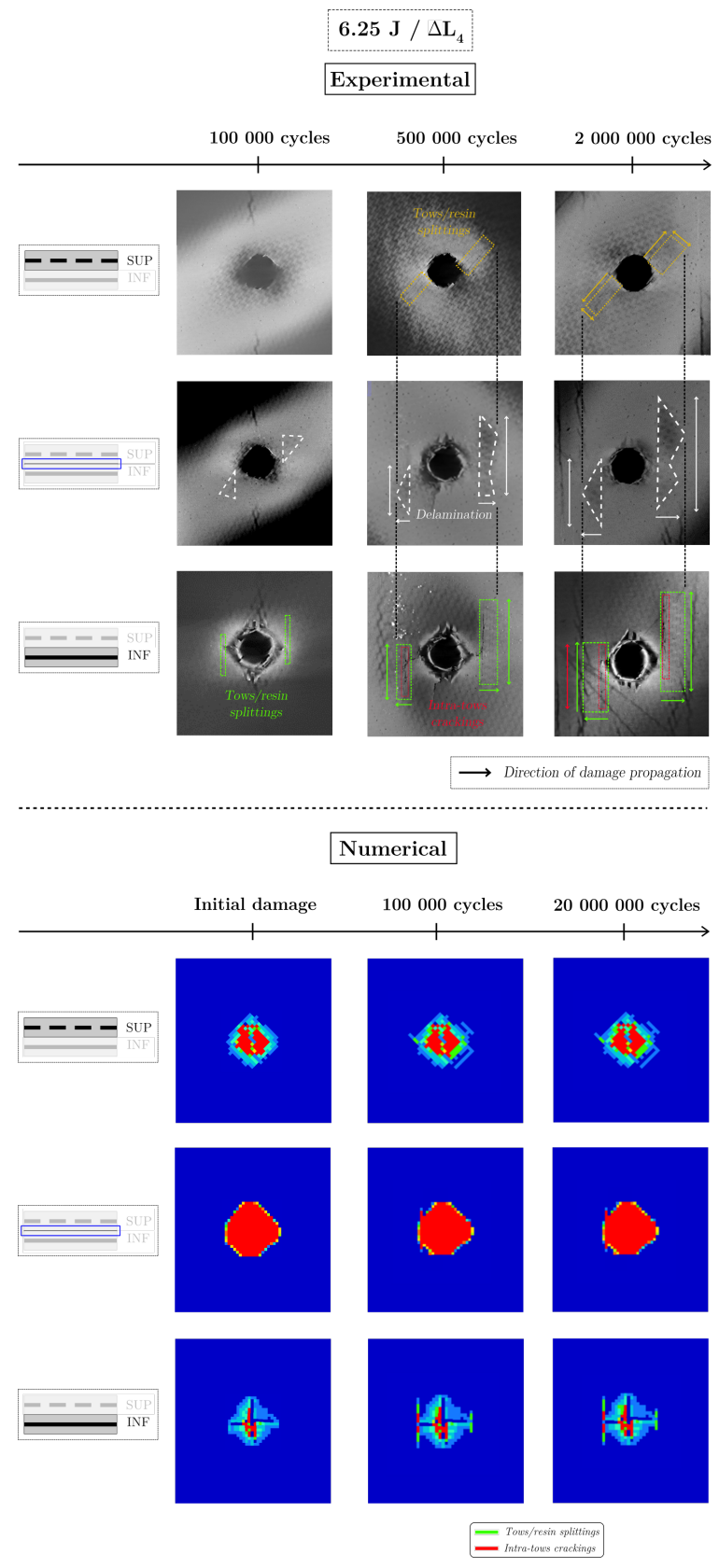

Figure 36: Post-impact damage propagation scenario for the configuration $\mathrm{C} 45 \mathrm{C} 0$ - Comparison experimental/numerical 


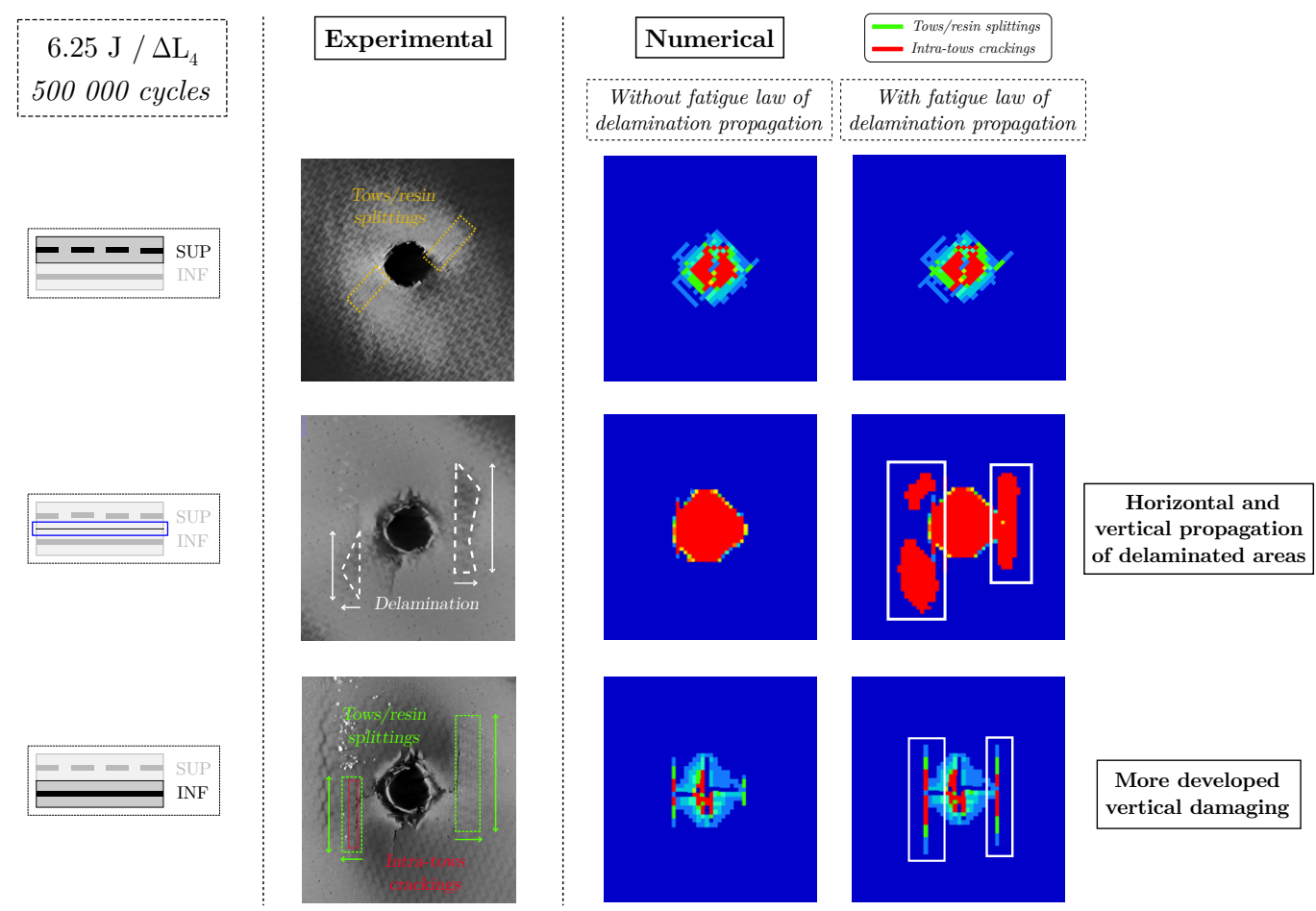

Figure 37: Post-impact damage propagation scenario for the configuration $\mathrm{C} 45 \mathrm{C} 0$ with introduction of a delamination propagation fatigue law in the modelling 


\begin{tabular}{cccc}
\hline Configuration & Representation & Upper ply & Lower ply \\
\hline \hline $\mathrm{C} 0 \mathrm{C} 0$ & Carbon $(0 / 90)^{\circ}$ & Carbon $(0 / 90)^{\circ}$ \\
$\mathrm{C} 45 \mathrm{C} 45$ & Carbon $\pm 45^{\circ}$ & Carbon $\pm 45^{\circ}$ \\
$\mathrm{C} 45 \mathrm{C} 0$ & & Carbon $\pm 45^{\circ}$ & Carbon $(0 / 90)^{\circ}$ \\
\hline
\end{tabular}

Table 1: Configurations of woven laminates

\begin{tabular}{cc}
\hline Initial velocity & Energy of impact \\
\hline \hline $1.5 \mathrm{~m} / \mathrm{s}$ & $2.25 \mathrm{~J}$ \\
$1.75 \mathrm{~m} / \mathrm{s}$ & $3 \mathrm{~J}$ \\
$2 \mathrm{~m} / \mathrm{s}$ & $4 \mathrm{~J}$ \\
$2.5 \mathrm{~m} / \mathrm{s}$ & $6.25 \mathrm{~J}$ \\
$3 \mathrm{~m} / \mathrm{s}$ & $9 \mathrm{~J}$ \\
\hline
\end{tabular}

Table 2: Different impact energies tested 


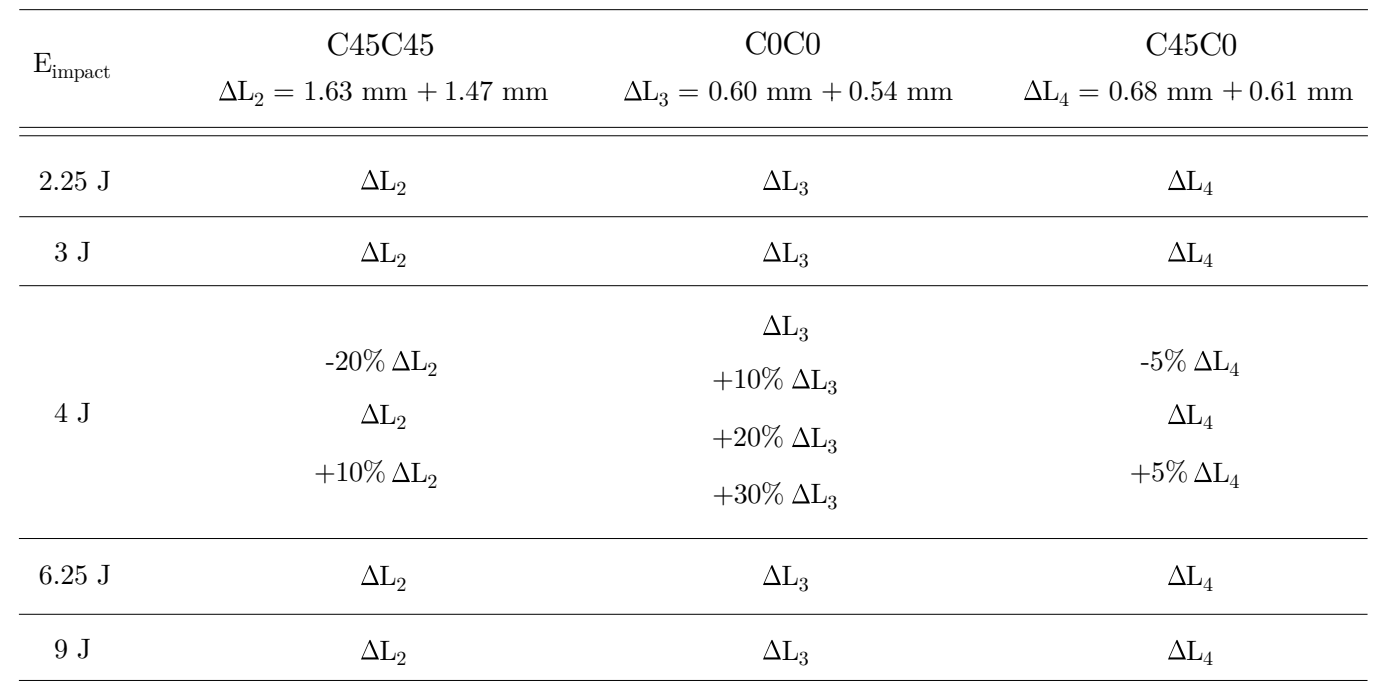

Table 3: Impact energies and displacements used for the post-impact fatigue tensile tests 


\begin{tabular}{|c|c|c|}
\hline $\mathrm{E}_{\text {impact }}$ & $\mathrm{N}_{\text {initiation }}$ & $\mathrm{N}_{\text {edge }}$ \\
\hline $3 \mathrm{~J}$ & 27500 & 120000 \\
\hline $4 \mathrm{~J}$ & 10000 & 60000 \\
\hline $6.25 \mathrm{~J}$ & 2000 & 15000 \\
\hline $9 \mathrm{~J}$ & 4000 & 20000 \\
\hline Displacement & $\mathrm{N}_{\text {initiation }}$ & $\mathrm{N}_{\text {edge }}$ \\
\hline$\Delta \mathrm{L}_{2}$ & 10000 & 60000 \\
\hline$+10 \% \Delta \mathrm{L}_{2}$ & 450 & 15000 \\
\hline
\end{tabular}

Table 4: Number of cycles necessary to initiate the damage propagation and reach the edges of the sample depending on the impact energy and the displacement level 


\begin{tabular}{crc} 
E $_{\text {impact }}$ & $\mathrm{N}_{\text {edges EXP }}$ & $\mathrm{N}_{\text {edges NUM }}$ \\
\hline \hline $3 \mathrm{~J}$ & 120000 & 100000 \\
$4 \mathrm{~J}$ & 60000 & 50000 \\
$6.25 \mathrm{~J}$ & 15000 & 8000 \\
$9 \mathrm{~J}$ & 20000 & 10000 \\
\hline
\end{tabular}

Table 5: Number of cycles necessary to reach the edges of the sample depending on the impact energy for the configuration $\mathrm{C} 45 \mathrm{C} 45$

\begin{tabular}{ccc}
\hline Displacement & $\mathrm{N}_{\text {edges EXP }}$ & $\mathrm{N}_{\text {edges NUM }}$ \\
\hline \hline $\mathrm{L}_{2}$ & 60000 & 50000 \\
$+10 \% \Delta \mathrm{L}_{2}$ & 15000 & 12000 \\
\hline
\end{tabular}

Table 6: Number of cycles necessary to reach the edges of the sample depending on the displacement level for the configuration $\mathrm{C} 45 \mathrm{C} 45$ 